\title{
Investigação de mecanismos genéticos e epigenéticos de distúrbios do crescimento humano
}

Investigation of genetic and epigenetic mechanisms in human growth disorders

Tese apresentada ao Departamento de Genética e Biologia Evolutiva do Instituto de Biociências da Universidade de São Paulo, para a obtenção de Título de Doutor em Ciências, na Área de Biologia/Genética. 
Orientadora: Dra. Angela M. Vianna Morgante 


\section{Resumo}

Parcela considerável de pacientes com distúrbios de crescimento não têm a causa de seus quadros clínicos estabelecida, incluindo aproximadamente $50 \%$ dos pacientes com diagnóstico clínico de síndrome de Silver-Russell (SRS) e 10-20\% dos pacientes com síndrome de Beckwith-Wiedemann (BWS). O objetivo deste estudo foi investigar as causas genéticas e epigenéticas de distúrbios de crescimento, de etiologia desconhecida, numa contribuição para o entendimento de mecanismos que regulam o crescimento. $\mathrm{O}$ estudo compreendeu: (1) a investigação de microdesequilíbrios cromossômicos, por aCGH; (2) a análise do perfil de expressão alelo-específica de genes sujeitos a imprinting (IG), por pirossequenciamento (PSQ) ou sequenciamento de Sanger; (3) a investigação do padrão de metilação global em pacientes com restrição de crescimento, utilizando microarray de metilação.

A casuística constituiu-se de 41 pacientes não aparentados, com distúrbios de crescimento, de etiologia desconhecida: (1) 25, com hipótese diagnóstica de SRS; (2) seis, com restrição de crescimento intrauterino e peso ao nascimento abaixo do $10^{\circ}$ percentil, associados a outros sinais clínicos; (3) sete, com hipótese diagnóstica de BWS; e (4) três, com macrossomia pré-natal ou pós-natal, associada a outros sinais.

A investigação de microdesequilíbrios cromossômicos foi realizada em 40 pacientes. Foram detectadas 58 variantes raras em 30/40 pacientes (75\%): 40 foram consideradas provavelmente benignas (18 pacientes, 45\%), 12, com efeito patogênico desconhecido (11 pacientes, 27,5\%), duas, provavelmente patogênicas (um paciente, 2,5\%) e quatro, patogênicas (três pacientes, 7,5\%). Essas frequências são comparáveis àquelas descritas em estudos que investigaram CNV em grupos de pacientes com distúrbios de crescimento e outras alterações congênitas, incluindo SRS, e mostram a importância da investigação de microdesequilíbrios cromossômicos nesses pacientes. A diversidade dos microdesequilíbrios cromossômicos identificados é reflexo da heterogeneidade clínica das casuísticas. Neste estudo, muitos dos pacientes com hipótese diagnóstica de SRS e BWS apresentavam sinais clínicos atípicos, explicando a ausência neles das alterações (epi)genéticas que causam essas síndromes. A identificação de CNV características de outras síndromes reflete a sobreposição de sinais clínicos com BWS e SRS.

A análise do perfil de expressão alelo-específica de IG foi realizada em um subgrupo de 18 pacientes com restrição de crescimento. Trinta IG com função em proliferação celular, crescimento fetal ou neurodesenvolvimento foram inicialmente selecionados. Após seleção de 
SNP transcritos com alta frequência na população, genotipagem de pacientes, genitores e indivíduos controle, determinação da expressão dos IG em sangue periférico e seu padrão de expressão (mono ou bialélico), 13 IG, expressos no sangue, tiveram a expressão aleloespecífica avaliada, sete deles por PSQ e seis por sequenciamento de Sanger. Alterações no perfil de expressão de dois genes, de expressão normalmente paterna, foram detectadas em 4/18 pacientes (22\%). Este estudo é o primeiro a utilizar pirossequenciamento e sequenciamento de Sanger na avaliação do perfil de expressão alelo-específica de IG, em pacientes com restrição de crescimento. Apesar de terem limitações, ambas as técnicas mostraram-se robustas e revelaram alterações de expressão alélica interessantes; entretanto, a relação dessas alterações com o quadro clínico dos pacientes permanece por esclarecer.

A investigação da metilação global do DNA foi realizada em subgrupo de 21 pacientes com restrição de crescimento e em 24 indivíduos controle. Dois tipos de análise foram realizados: (1) análise diferencial de grupo e (2) análise diferencial individual. Na primeira análise, em que foi comparado o padrão de metilação do grupo de pacientes com quadro clínico sugestivo de SRS ( $n=16)$ com o do grupo controle $(n=24)$, não houve indicação de hipo ou hipermetilação global no grupo SRS. Na segunda análise, foi comparado o padrão de metilação de cada um dos 21 pacientes com restrição de crescimento e dos 24 indivíduos controle, com o padrão de metilação do grupo controle. O número médio de $\mathrm{CpG}$ hipermetilados e de segmentos diferencialmente metilados (SDM) foi significativamente maior nos pacientes. Foram identificados 82 SDM hipermetilados, estando 57 associados a gene(s) (69,5\%), em 16 pacientes, e 51 SDM hipometilados, 41 deles associados a gene(s) (80,4\%), em 10 pacientes. A análise de ontologia genética dos 61 genes associados aos SDM hipo ou hipermetilados nos pacientes destacou genes que atuam no desenvolvimento e na morfogênese do sistema esquelético e de órgãos fetais, e na regulação da transcrição gênica e de processos metabólicos. Alterações de metilação em genes que atuam em processos de proliferação e diferenciação celulares e crescimento foram identificadas em 9/20 dos pacientes $(45 \%)$, sugerindo implicação clínica. Não foi detectada alteração epigenética comum aos pacientes com diagnóstico clínico de SRS, explicável provavelmente pela heterogeneidade clínica. A investigação de metilação global, utilizando microarray, produziu novos dados que podem contribuir para a compreensão de mecanismos moleculares que influenciam o crescimento pré- e pós-natal.

$\mathrm{Na}$ translocação aparentemente equilibrada - t(5;6)(q35.2;p22.3)dn, detectada em paciente com suspeita clínica de SRS, a interrupção de um gene, pela quebra no cromossomo 6, pode ser a causa do quadro clínico; alternativamente, a translocação pode ter impactado a 
regulação de genes de desenvolvimento localizados próximos aos pontos de quebra. A análise de expressão em sangue periférico mostrou que os níveis de cDNA do gene, interrompido pelo ponto de quebra da translocação, estavam reduzidos à metade. Além de sinais típicos da SRS, a paciente apresentava algumas características clínicas sugestivas de displasia cleidocraniana. Assim, a translocação $\mathrm{t}(5 ; 6)$ pode ter alterado a interação de genes de desenvolvimento e seus elementos reguladores, levando à desregulação de sua expressão espaço-temporal, e resultando num fenótipo atípico, com características sobrepostas de mais de uma síndrome genética. 
A large number of patients with growth disorders do not have the cause of their clinical phenotype established, including about $50 \%$ of patients with Silver-Russell syndrome (SRS), and 10-20\% of patients with Beckwith-Wiedemann syndrome (BWS). The aim of this study was to investigate the (epi)genetic causes of growth disorders of unknown etiology, in a contribution to the understanding of growth regulation. The study included: (1) the investigation of submicroscopic chromosomal imbalances, by aCGH, (2) the analysis of the allele-specific expression profile of imprinted genes (IG), by pyrosequencing (PSQ) or Sanger sequencing, in patients with growth restriction; (3) the investigation of global methylation pattern in patients with growth restriction, using methylation microarray.

The cohort consisted of 41 unrelated patients with growth disorders: (1) 25, with the diagnostic hypothesis of SRS; (2) six, with intrauterine growth restriction and birth weight below the 10th centile, associated with other clinical signs; (3) seven, with the diagnostic hypothesis of BWS; and (4) three, with prenatal or postnatal macrosomia, associated with other clinical signs.

Chromosomal microdeletions and microduplications were investigated in 40 patients. Fifty-eight rare variants were detected in 30/40 patients (75\%): 40 were considered likely benign (18 patients, 45\%), 12, of unknown pathogenic significance (11 patients, 27.5\%), two, likely pathogenic (one patient, 2.5\%), and four, pathogenic (three patients, 7.5\%). These frequencies are similar to those described in studies investigating CNVs in groups of patients with growth disorders and other congenital abnormalities, including SRS, and show the importance of investigating chromosomal microimbalances in these patients. The diversity of CNVs identified can be attributed to the clinical heterogeneity of these cohorts. In this study, many of the patients, with the diagnostic hypothesis of SRS or BWS, had atypical clinical signs, thus explaining the absence of specific SRS/BWS (epi)genetic mutations. The identification of CNVs, known to be causative of other syndromes, reflected the overlapping of some of their clinical features with those of SRS and BWS.

The analysis of IG allele-specific expression profile was performed in a subgroup of 18 patients with growth restriction. Thirty IGs were initially selected, based on their association with cell proliferation, fetal growth or neurodevelopment. Transcribed SNPs with high frequency in the general population were selected for the genotyping of patients, parents and control subjects, determination of IG expression in peripheral blood, and of the monoallelic or biallelic expression pattern. The allele-specific expression of 13 IGs expressed 
in blood was then investigated in patients (seven of them by PSQ and six by Sanger sequencing). Expression alterations of two normally paternally expressed genes were detected in $4 / 18$ patients (22\%). This study is the first to use pyrosequencing and Sanger sequencing in the evaluation of IG allele-specific expression profile, in patients with growth restriction. Despite the limitations, both techniques have proved to be robust, and revealed interesting alterations in allelic expression; however, the causal relationship of these alterations with the clinical phenotypes remained unclear.

The investigation of the global DNA methylation was performed in a subgroup of 21 patients with growth restriction, and in 24 control subjects. Two types of analysis were performed: (1) group differential analysis, and (2) individual differential analysis. In the first analysis, the methylation pattern obtained for the group of patients with the diagnostic hypothesis of SRS ( $n=16)$ was compared to that of the control group $(n=24)$; no bias towards DNA hypo or hypermethylation was detected in the SRS group. In the second analysis, the methylation patterns of each of the 21 patients with growth restriction, and each of the 24 control subjects were compared to the methylation pattern of the control group. The average numbers of hypermethylated CpGs and of differentially methylated segments (DMSs) were significantly higher in the patients. In total, 82 hypermethylated DMSs - 57 associated with gene(s) (69.5\%), in 16 patients, and 51 hypomethylated DMSs - 41 associated with gene(s) $(80.4 \%)$, in 10 patients, were identified. Gene ontology analysis of the 61 DMS-associated genes highlighted genes involved in development and morphogenesis of the skeletal system and fetal organs, and also in the regulation of gene transcription and metabolic processes. Methylation changes in genes involved with cellular proliferation and differentiation, and growth were identified in 9/20 patients (45\%), suggesting clinical implications; an epigenetic mutation common to SRS patients was not detected, likely due to the clinical heterogeneity of the cohort. The data generated by this global methylation analysis, using microarray, might contribute to the understanding of molecular mechanisms in growth restriction.

In an apparently balanced translocation $-\mathrm{t}(5 ; 6)(\mathrm{q} 35.2 ; \mathrm{p} 22.3) \mathrm{dn}$, detected in a patient with the diagnostic hypothesis of SRS, a gene found to be disrupted by the chromosome 6 breakpoint might explain the phenotype; alternatively, the translocation might have impacted the regulation of developmental genes in the vicinity of breakpoints. Expression analysis showed a significant decrease in the disrupted gene cDNA levels in the patient's blood cells, as expected. In addition to the SRS typical signs, the patient presented clinical features suggestive of cleidocranial dysplasia. Thus, the translocation $\mathrm{t}(5 ; 6)$ might have altered the interaction of developmental genes and regulatory elements, leading to misregulation of 
spatiotemporal gene expression, thus resulting in an atypical phenotype, with overlapping features of more than one genetic syndrome. 


\section{Introdução}

\section{I.1.1 Os distúrbios de crescimento em humanos}

O crescimento adequado no útero é essencial para uma vida longa e saudável e o peso ao nascimento (PN) entre os percentis 10 e 90 é considerado adequado para a idade gestacional (Cunningham e col., 2001). Desvios extremos no crescimento fetal podem levar a diversas complicações perinatais e neonatais. Além disso, há evidência de que efeitos do crescimento fetal fora da normalidade se estendem até a idade adulta, podendo afetar, inclusive, gerações seguintes (revisão em Das e Sysyn, 2004).

A restrição de crescimento intrauterino (RCIU) resulta em recém-nascido pequeno para a idade gestacional (peso abaixo do $3^{\circ}$ ou do $10^{\circ}$ percentil). Aproximadamente $3-10 \%$ dos recém-nascidos são considerados pequenos para a idade gestacional; embora a maioria dessas crianças retomem o crescimento nos primeiros anos de vida, 10-15\% permanecem pequenas depois dos 2 anos de idade e representam problema importante de saúde pública (revisões em Saenger e Reiter, 2012; Dauber e col., 2014). A RCIU é observada em aproximadamente $50 \%$ dos natimortos sem malformações e está associada a $10 \%$ da mortalidade perinatal (Moore e col., 2015). Além da mortalidade, cerca de 12 vezes aumentada em relação àqueles com peso adequado para a idade gestacional, recém-nascidos que tiveram RCIU podem apresentar problemas imediatos, como hipotermia, hipoglicemia, hemorragia pulmonar e encefalopatia (revisão em Monk e Moore, 2004). As causas da restrição de crescimento pré- e pós-natal são numerosas. Em uma criança com baixa estatura, deve-se considerar como possíveis causas, além de variação normal, distúrbios nutricionais, doenças ósseas, fatores emocionais, infecções, doenças metabólicas, distúrbios endócrinos, e síndromes associadas a teratógenos ou de etiologia genética (revisão em Hall, 2010).

$\mathrm{O}$ crescimento intrauterino exacerbado resulta em recém-nascido grande para a idade gestacional, ou macrossômico (peso acima do $90^{\circ}$ ou do $95^{\circ}$ percentil). A macrossomia pode ser generalizada, quando atinge todo o corpo, ou localizada (hemi-hiperplasia, macrocefalia ou macrodactilia) (revisão em Yachelevich e col., 2015). Estima-se que 5-8\% dos recémnascidos sejam macrossômicos, podendo apresentar diversas complicações neonatais, como hemorragia pós-parto, distocia do ombro, lesão do plexo braquial, fratura clavicular, encefalopatia hipóxico-isquêmica, hipoglicemia e dificuldade respiratória, que podem levar ao óbito (Weissmann-Brenner e col., 2012). O crescimento exacerbado pré-natal pode resultar de variantes familiares normais, de diabete materna, e ter causas genéticas, entre elas o 
hiperinsulinismo congênito. Na infância, o diagnóstico diferencial de crianças macrossômicas inclui variação normal, obesidade nutricional, endocrinopatias, doenças do tecido conjuntivo e outras patologias com causa genética (revisão em Yachelevich e col., 2015).

O peso e o tamanho ao nascimento e o progresso do crescimento pós-natal são, portanto, fatores determinantes para a sobrevivência perinatal, estando certamente sujeitos a intensa pressão seletiva ao longo da evolução (revisões em Dunger e col., 2006; Yaghootka e col., 2012). Existem evidências de que a restrição ou excesso de crescimento fetal podem predispor a diversas morbidades pós-natais, com consequências que se estendem até a vida adulta, como doenças cardiovasculares, intolerância à glicose e obesidade (GascoinLachambre e col., 2010). Os mecanismos condicionadores dessas associações ainda não estão elucidados, mas é provável que atuem fatores genéticos e ambientais (revisão em Yaghootka e col., 2012).

A etiologia dos distúrbios de crescimento é geralmente multifatorial, incluindo fatores genéticos, epigenéticos e ambientais em graus variados (revisão em Monk e Moore, 2004). Intercorrências durante a gravidez, como insuficiência placentária, pré-eclâmpsia, diabetes materna, restrição da nutrição materna, tabagismo, uso de drogas, álcool e infecções virais, podem resultar em distúrbios de crescimento pré- e pós-natal. A disponibilidade excessiva ou reduzida de glicose materna para o feto afeta diretamente o seu crescimento; glicemia excessiva pode resultar em recém-nascido macrossômico, enquanto que níveis reduzidos de glicose foram associados com restrição do crescimento fetal (Cunningham e col., 2001). Idade materna elevada, e baixo peso materno ou sobrepeso antes da gravidez são outros fatores de risco a serem considerados (revisão em Saenger e Reiter, 2012).

Os distúrbios de crescimento podem ser constitutivos, isto é, dependentes de características familiais, ou estarem associados a diferentes patologias. Existem várias condições em humanos que incluem o déficit de crescimento ou o crescimento exacerbado entre suas características, como distúrbios hormonais endócrinos, doenças metabólicas, distúrbios nutricionais, malformações congênitas, e síndromes com etiologia genética conhecida ou com mecanismos genéticos ainda por esclarecer (revisão em Ambler, 2012). 


\section{I.1.2 A genética dos distúrbios de crescimento}

A altura é característica multifatorial com alto componente hereditário. Estudos de associação considerando o genoma total (GWAS; Genome-wide Association Studies), avaliando centenas de milhares ou milhões de polimorfismos de nucleotídeo único (SNP; Single Nucleotide Polymorphisms), em grandes amostras populacionais, têm investigado a influência de fatores genéticos na altura. Um desses estudos levou à conclusão de que pelo menos 180 lócus estão associados à altura do adulto. No entanto, a contribuição de cada lócus era pequena, explicando juntos apenas cerca de $10 \%$ da variação fenotípica da altura (Lango e col., 2010). Mas, até $40 \%$ da variância da altura pode ser explicada, ao serem considerados simultaneamente todos os SNP (Yang e col., 2010). Uma meta-análise de GWAS, em populações europeias, identificou dois lócus [ADCY5 (adenylate cyclase 5) e CCNL1 (cyclin L1)] significativamente associados com crescimento fetal e peso ao nascimento; no entanto, o mecanismo pelo qual essas variantes genéticas alteram o crescimento fetal ainda é desconhecido (Freathy e col., 2010). Outros quatro lócus [CDKAL1 (CDK5 regulatory subunit associated protein 1-like 1), HHEX-IDE (hematopoietically expressed homeobox/ insulin-degrading enzyme), TCF7L2 (transcription factor 7-like 2 (T-cell specific, HMG-box)) e GCK (glucokinase (hexokinase 4))] mostraram potencial de associação (Yaghootka e col., 2012). Cinco dos seis lócus detectados nesses dois estudos também foram associados à diabetes tipo 2 (T2D; MIM \#125853), com efeitos sobre o peso ao nascimento decorrentes do genótipo fetal ou do genótipo materno.

Outros estudos investigaram a associação de variantes genéticas, em fatores de crescimento fetais ou maternos específicos, com parâmetros de crescimento fetal, como peso e tamanho ao nascimento (revisão em Ishida e Moore, 2013). Associações positivas foram identificadas com variantes de genes sujeitos a imprinting genômico, importantes para o crescimento fetal, como IGF2 (insulin-like growth factor 2), H19 (H19, imprinted maternally expressed transcript), INS (Insulin), PHLDA2 (pleckstrin homology-like domain, family A, member 2), e de outros fatores de crescimento, tais como IGF1 (insulin-like growth factor 1) e IGF2R (insulin-like growth factor 2 receptor).

Além de variantes genéticas comuns descritas em estudos de associação que explicam parte da variabilidade fenotípica do crescimento, existem mecanismos raros com efeito maior, como as alterações cromossômicas estruturais, variações no número de cópias de DNA, dissomias uniparentais (UPD; Uniparental Disomy), e as mutações genéticas e epigenéticas em genes específicos. Esses mecanismos geralmente resultam em distúrbios de crescimento 
associados a outros sinais clínicos, constituindo síndromes genéticas. As causas genéticas mais comuns de baixa estatura, sindrômica ou isolada, incluem as alterações em genes da via de hormônio de crescimento, mutações no fator de transcrição SHOX (short stature homeobox) e a monossomia do cromossomo X em mulheres (revisão em Zahnleiter e col., 2013). Alterações cromossômicas estão presentes em aproximadamente $20 \%$ dos fetos com RCIU (revisão em Monk e Moore, 2004). No entanto, as causas da restrição de crescimento permanecem desconhecidas em até $80 \%$ dos pacientes (revisão em Seaver e col., 2009). Exemplos de síndromes de restrição de crescimento de estabelecimento pré-natal incluem as síndromes de Silver-Russell (SRS; MIM \#180860), 3-M (MIM \#273750, 612921, 614205), de Bloom (MIM \#210900), de Dubowitz (MIM \#223370) e IMAGE (MIM \#614732). Uma revisão sobre síndromes de restrição de crescimento foi recentemente publicada por Dauber e col. (2014).

As síndromes de crescimento exacerbado em geral apresentam fenótipos que se sobrepõem, incluindo além de macrossomia pré e/ou pós-natal, macroglossia, organomegalia, defeitos da parede abdominal (onfalocele), hipoglicemia e, principalmente, predisposição aumentada a desenvolver tumores embrionários (revisão em Yachelevich e col., 2015). Essa sobreposição de características clínicas dificulta o diagnóstico específico e a causa genética das síndromes de crescimento exacerbado ainda é desconhecida em 20-40\% dos casos (Malan e col., 2010). Alguns exemplos de síndromes clássicas de crescimento exacerbado de estabelecimento pré-natal são a síndromes de Sotos (MIM \#117550), de BeckwithWiedemann (BWS; MIM \#130650), de Simpson-Golabi-Behmel (MIM \#312870) e de Weaver (MIM \#277590). Uma revisão sobre essas síndromes foi recentemente publicada por Yachelevich (2015).

\section{I.1.3 A regulação do crescimento fetal}

O crescimento fetal é processo complexo e dinâmico, regulado por fatores (epi)genéticos e ambientais. As estimativas indicam que, sob circunstâncias normais, aproximadamente um terço do tamanho do recém-nascido seja explicado por fatores genéticos e outro terço, por fatores ambientais, o restante, por fatores não determinados (revisão em Ambler, 2002). Estimativas da herdabilidade do peso ao nascimento estão por volta de 10 a 40\% (revisão em Yaghootka e col., 2012). Dois genomas diferentes contribuem para essa variabilidade genética: genes fetais têm papel importante no crescimento no início da vida fetal, enquanto que genes maternos modulam o ambiente intrauterino e, juntamente aos 
nutrientes e hormônios, têm influência predominante sobre o crescimento fetal no restante da gravidez (revisão em Yaghootka e col., 2012).

A interação entre fatores maternos, placentários e fetais no ambiente intrauterino são determinantes para o desenvolvimento fetal (Figura I.1). Fatores maternos incluem paridade, tempo de gestação, estatura e peso da mãe, incluindo o peso materno ao nascimento (revisão em Dunger e col., 2006). A placenta mantém e impulsiona o desenvolvimento embrionário, fornecendo um ambiente para o crescimento do feto, coordenando as diferentes fases da embriogênese, e servindo como interface para interações materno-fetais (revisão em Lambertini, 2014). O crescimento fetal depende da disponibilidade adequada de nutrientes e a placenta tem papel chave na transferência desses nutrientes e de oxigênio da mãe para o feto (Cunningham e col., 2001; Bloomfield e col., 2013).

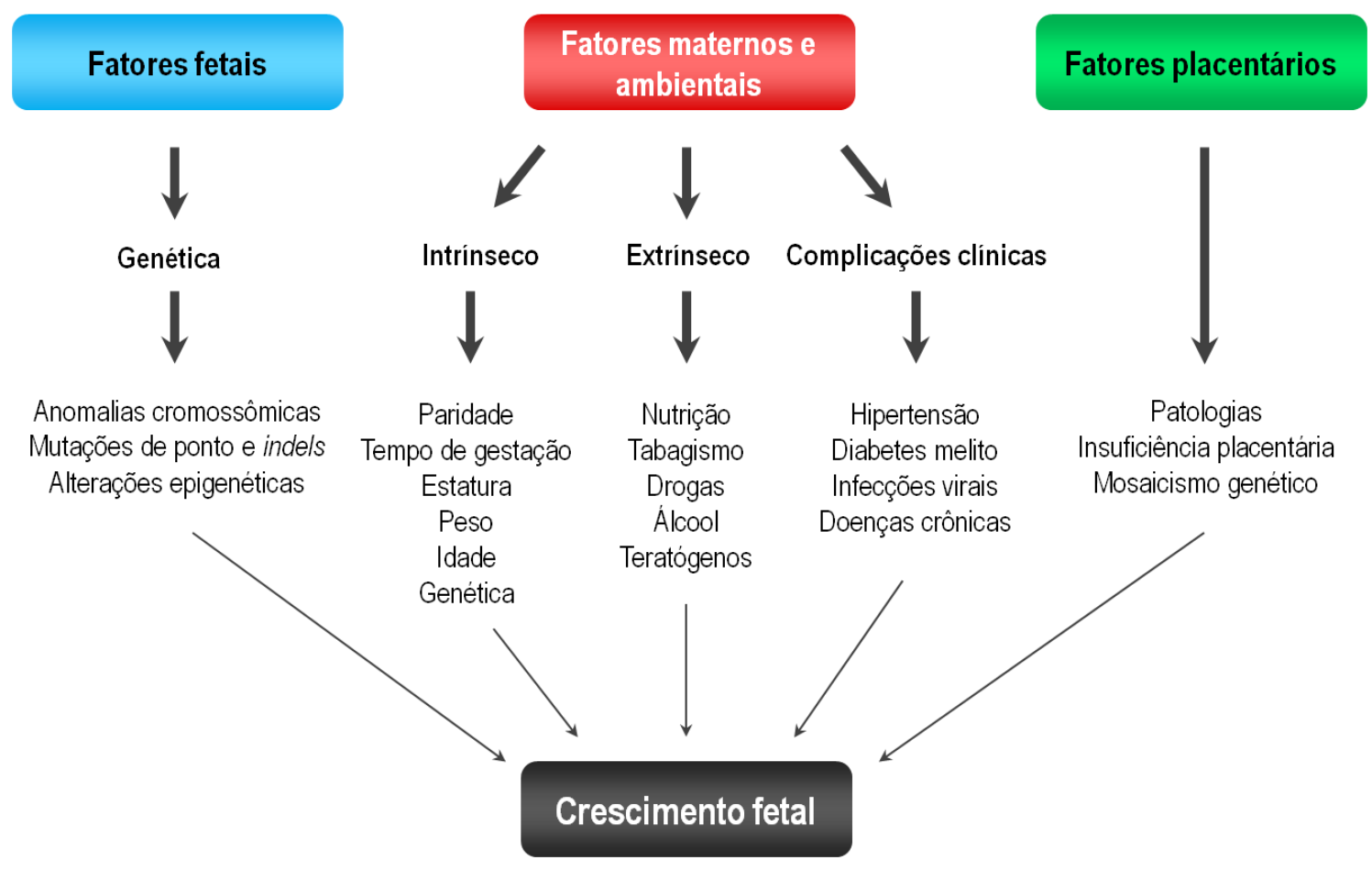

Figura I.1 - Fatores maternos, placentários, fetais e ambientais que atuam, em conjunto, na determinação do crescimento fetal.

O crescimento fetal é regulado pela integração entre os nutrientes providos pela mãe e os fatores de crescimento produzidos pelo feto, que incluem a insulina e os fatores semelhantes à insulina, seus receptores e proteínas ligantes (sistema IGF) (Bloomfield e col., 2013). A insulina é secretada pelas células pancreáticas fetais, principalmente durante a segunda metade da gestação, e estimula o crescimento. Os fatores de crescimento semelhantes 
à insulina são produzidos por praticamente todos os órgãos fetais, desde o início do desenvolvimento, e têm papel crucial na divisão e diferenciação celulares. Por outro lado, proteínas ligantes aos fatores de crescimento semelhantes à insulina restringem o crescimento (Cunningham e col., 2001).

Estudos em animais knockout demonstraram a importância dos genes Ins, Igfl, Igf2 e seus respectivos receptores, Insr (insulin receptor), Igflr (insulin-like growth factor 1 receptor) e $I g f 2 r$, na regulação do crescimento do feto e da placenta durante a gestação (revisões em Dunger e col., 2006; Gicquel e Le Bouc, 2006). Mutações raras em humanos corroboraram o papel dessas proteínas na regulação do crescimento fetal em humanos. Um exemplo dessa relação veio do estudo de indivíduos nascidos com alterações no desenvolvimento pancreático ou defeito na ativação do receptor de insulina, que apresentaram diminuição do crescimento fetal e do tecido adiposo (Ogilvy-Stuart e col., 2001). Outro estudo relatou recém-nascidos com baixo peso para a idade gestacional, que eram portadores de mutações no gene IGF1 (Bonapace e col., 2003; Woods e col., 2006). Além disso, maior ou menor número de cópias do gene $I G F l R$ foram associadas com aumento ou diminuição do crescimento pré- e pós-natal, respectivamente, indicando que o número de cópias de $I G F 1 R$ pode influenciar o crescimento em humanos (Okubo e col., 2003). Outro exemplo de regulação do crescimento fetal em humanos veio da observação das manifestações clínicas causadas por alterações de expressão do gene sujeito a imprinting IGF2. Normalmente, somente a cópia paterna desse gene é transcricionalmente ativa. A super-expressão de $I G F 2$, devido à perda do imprinting materno, é uma das causas da síndrome de BeckwithWiedemann, caracterizada principalmente pelo crescimento pré- e/ou pós-natal exacerbado; mutações opostas, levando a supressão da expressão do gene $I G F 2$, resultam na síndrome de Silver-Russell, conhecida por apresentar grave RCIU entre os seus sinais clínicos. Apesar de o sistema IGF de fatores de crescimento ser o mais bem estudado na regulação do crescimento fetal, variações na expressão de outros genes e seus produtos também são relevantes (revisão em Ambler, 2002).

\section{I.1.4 O imprinting genômico e seu papel no crescimento fetal}

A expressão gênica de cada tipo celular é controlada por vários mecanismos. Para a maioria dos genes, ambos ou nenhum dos alelos são expressos, de acordo com o estado ou a identidade de uma determinada célula. No entanto, muitos genes têm expressão monoalélica, como a maioria daqueles localizados no cromossomo $\mathrm{X}$ inativo, genes autossômicos com 
expressão monoalélica aleatória, aqueles controlados por polimorfismos em elementos regulatórios in cis, e genes sujeitos a imprinting genômico (revisão em Chess, 2012). Os genes sujeitos a imprinting (IG; Imprinted Genes) têm expressão monoalélica dependente da origem parental; assim, para cada IG, apenas um alelo é expresso, o materno ou o paterno. A transcrição desses genes é regulada por mecanismos epigenéticos, dos quais a metilação do DNA é fundamental na diferenciação dos genomas materno e paterno (revisão em Reik e Walter, 2001). Nos mamíferos, eutérios e marsupiais, o imprinting tem papel crucial no desenvolvimento da placenta e do embrião, no crescimento fetal, e no neurocomportamento e no metabolismo, após o nascimento. O fenômeno do imprinting não é observado em mamíferos prototérios ou em outros vertebrados. O imprinting também evoluiu de forma independente em plantas angiospermas, nas quais o endosperma tem função semelhante à placenta (revisão em Ishida e Moore, 2013)

Até a década de 80, acreditava-se que a informação genética de cada genitor contribuía de forma equivalente para o desenvolvimento do embrião e a partenogênese, conhecida em várias espécies de animais, apoiava essa conclusão. Porém, a inviabilidade da partenogênese em mamíferos levantou questões sobre a equivalência da contribuição dos genomas materno e paterno para o desenvolvimento do embrião. A principal hipótese era de que a homozigose quanto a alelos recessivos letais seria responsável pela perda dos embriões uniparentais (Graham, 1974). Nova evidência veio da observação de que a maioria das molas hidatiformes completas, conceptos com proliferação abundante do trofoblasto, normalmente sem embrião associado, possuíam dois conjuntos haplóides de cromossomos paternos, sem qualquer cromossomo materno, indicando que os genomas paterno e materno tinham efeitos diferentes durante o desenvolvimento humano, e que genes paternos eram importantes para o desenvolvimento do trofoblasto (Kajii e Ohama, 1977).

Dois estudos posteriores foram cruciais para mostrar que havia de fato diferença funcional entre os genomas parentais em mamíferos (Surani e col., 1984; McGrath e Solter, 1984). Ambos utilizaram transplante de pró-núcleos para gerar embriões de camundongos com conjuntos de cromossomos de apenas um dos genitores. Os poucos embriões que possuíam dois pró-núcleos femininos (ginogenéticos) apresentaram restrição de crescimento marcante e o desenvolvimento dos tecidos extraembrionários foi particularmente reduzido. Por outro lado, embriões que receberam dois pró-núcleos masculinos (androgenéticos) apresentaram crescimento exacerbado dos tecidos extraembrionários, corroborando os achados em molas hidatiformes. Somente os embriões controle, que receberam um pró-núcleo de cada sexo, desenvolviam-se a termo. Com base nesses resultados, os autores dos dois 
estudos concluíram que a homozigose quanto a alelos recessivos letais não era o principal fator responsável pela inviabilidade dos embriões ginogenéticos e androgenéticos de camundongos, mas que deveria haver um mecanismo específico de imprinting, que marcava diferencialmente os genomas parentais durante a gametogênese e que explicaria a necessidade de o zigoto possuir ambos os pró-núcleos, materno e paterno, para ter desenvolvimento normal. Apesar de terem a mesma quantidade de informação genética, a contribuição materna e paterna para o genoma do embrião não seria funcionalmente equivalente.

Esses achados foram refinados por estudos como o de Cattanach e Kirk (1985), que demonstraram que os efeitos da origem parental são específicos a certas regiões do genoma. Por meio de cruzamentos entre camundongos portadores de translocações cromossômicas Robertsonianas ou recíprocas, foram gerados embriões que herdavam cromossomos ou segmentos cromossômicos específicos de apenas um genitor. Os camundongos produzidos apresentaram fenótipos normais ou anormais, dependendo do cromossomo ou do segmento presente em dissomia uniparental. Os fenótipos se manifestavam como exacerbação ou restrição de crescimento, além de distúrbios de comportamento. Um exemplo marcante foi o segmento proximal do cromossomo 11 de camundongo: ao herdar duas cópias maternas, a prole apresentava restrição de crescimento; o fenótipo oposto era observado quando a prole herdava duas cópias paternas desse segmento. Os autores sugeriram que havia uma forma de marcação (imprinting) que afetava a atividade gênica nos cromossomos parentais de maneira recíproca e era responsável pelos fenótipos contrastantes observados nos camundongos.

No começo da década de 90, os primeiros IG foram descobertos - Igf2, Igf $2 r$ e H19 - e foi comprovado que realmente eram expressos diferencialmente nos cromossomos parentais (revisão em Reik e Walter, 2001). Genes sujeitos a imprinting expressos no feto e na placenta podem potencialmente afetar o crescimento fetal devido aos efeitos da demanda fetal por nutrientes ou do fornecimento de nutrientes pela placenta (revisão em Peters, 2014). A perda de imprinting desses genes pode resultar em aumento ou redução do crescimento fetal e placentário. Muitos desses genes são expressos em tecidos fetais importantes na regulação do metabolismo pós-natal e são regulados negativamente após o nascimento (Charalambous e col., 2007).

Estudos em camundongos knockout quanto a determinados IG mostraram a importância desses genes na regulação do crescimento da placenta e do embrião. Deleções dos genes de expressão paterna Igf2, Mest (mesoderm specific transcript), Peg3 (paternally expressed 3) e Ins2 (insulin II) resultaram em RCIU, enquanto a situação oposta foi observada em camundongos com perda de função de H19, Igf2r e Grb10 (growth factor receptor-bound 
protein 10), genes com expressão exclusivamente materna, que resultaram em exacerbação de crescimento do embrião (revisões em Monk e Moore, 2004; Cleaton e col., 2014; Moore e col., 2015). Fenótipo semelhante de crescimento exacerbado foi observado em camundongos com super-expressão do gene Igf2, devida à perda do imprinting materno (Sun e col., 1997).

O processo de imprinting leva a haploidia funcional; dessa forma, os IG perdem a vantagem protetora da diploidia, tornando as regiões sujeitas a imprinting potencialmente vulneráveis, como é visto em doenças associadas a imprinting, discutidas mais adiante. Provavelmente deve haver vantagens seletivas para a evolução e manutenção desse fenômeno. A restrição do imprinting aos mamíferos térios indica que a placentação e o imprinting surgiram em momentos similares na evolução e podem estar correlacionados (revisão em Cleaton e col., 2014).

A associação entre a aquisição do imprinting e da placenta durante a evolução levou a elaboração de algumas hipóteses para explicar o surgimento de imprinting genômico. Duas teorias são amplamente citadas - a teoria kinship e a teoria da coadaptação - e têm implicações para ambas as fases pré e pós-natal. De acordo com a teoria kinship, ou teoria do conflito parental, os IG evoluíram para refletir os interesses maternos e paternos pelo fornecimento de nutrientes no período fetal. Assim, esses genes apresentariam funções antagônicas: genes de expressão paterna promoveriam o crescimento do feto pela utilização de recursos maternos, para otimizar a chance de sobrevivência perinatal, enquanto que genes de expressão materna contrabalanceariam isso por limitar os recursos ao feto e restringir o crescimento fetal, garantindo assim a sobrevivência materna para futuras gestações e igualdade de fornecimento de nutrientes entre sua prole (Moore e Haig, 1991).

A teoria da coadaptação propõe que os IG atuariam em conjunto para otimizar o desenvolvimento fetal, além do fornecimento de nutrientes e cuidados maternos. Durante o desenvolvimento dos mamíferos, um conjunto complexo de interações ocorre entre o feto, a placenta e o hipotálamo da mãe que influenciam o crescimento fetal, o desenvolvimento do cérebro, o fornecimento de recursos maternos em ambas as fases pré e pós-natal, e o cuidado materno após o nascimento. A regulação dessas funções pelo imprinting provavelmente seria devido à coadaptação genitores-prole através da seleção de, principalmente, genes de expressão paterna coexpressos na placenta e no hipotálamo da mãe (Keverne e col., 2008).

Em humanos, a perda do imprinting recapitula os fenótipos demonstrados nos estudos com camundongos knockout. A desregulação da expressão de IG foi associada a gestações com RCIU, a medidas de crescimento fetal, como perímetro cefálico e peso ao nascimento, e ao neurocomportamento do recém-nascido (Lambertini, 2014; Moore e col., 2015). A perda 
do imprinting também causa síndromes, caracterizadas principalmente por alterações de crescimento pré- e pós-natal, do metabolismo e do neurocomportamento após o nascimento e, mais recentemente, tem sido relacionada a doenças comuns como obesidade, diabetes melito e câncer.

\section{I.1.5 A regulação do imprinting genômico}

Atualmente, são conhecidos aproximadamente 150 genes sujeitos a imprinting em camundongos (MouseBook Imprinting Catalogue - http://www.mousebook.org/mousebookcatalogs/imprinting-resource). Em humanos, cerca de 100 IG já foram caracterizados, e muitos outros foram sugeridos como candidatos (Catalogue of Parent of Origin Effects http://igc.otago.ac.nz/home.html; Geneimprint - http://www.geneimprint.com/site/genes-byspecies.Homo+sapiens.any). A maior parte dos IG em humanos é conservada em camundongos, mas alguns são exclusivos de uma espécie ou da outra. Análises de transcriptoma e de metiloma aplicando-se tecnologias de larga escala, tais como microarrays e sequenciamento de nova geração, têm sido amplamente utilizados na busca por novos IG (Court e col., 2014; Docherty e col., 2014; Babak e col., 2015; Baran e col., 2015).

Os IG se expressam em uma ampla gama de tecidos, mas particularmente na placenta e no cérebro (revisão em Davies e col., 2007). De fato, acredita-se que 70\% dos IG sejam reguladores do crescimento fetal e do desenvolvimento cerebral em mamíferos (revisão em Reik e Walter, 2001). Cerca de um terço dos IG são RNA não codificadores (ncRNA), muitos dos quais, RNA pequenos (revisão em Morison e col., 2005). Apesar de alguns IG ocorrerem isolados ou em pares no genoma, aproximadamente $60 \%$ dos IG em humanos estão arranjados em clusters de três ou mais genes em segmentos de até 2,3 Mb, estruturalmente conservados entre humanos e camundongos. Dez clusters de IG foram caracterizados em humanos, mapeados em 2q33.3, 6q24.2, 7q21.3, 7q32.2, 11p15.5p15.4, 14q32.2, 15q11.2, 19q13.43 e 20q13.32. A maioria deles consiste de genes de expressão materna e paterna, pelo menos um IG de ncRNA (miRNA, snoRNA ou lncRNA), além de genes não sujeitos a imprinting (revisões em Henckel e Arnaud, 2010; Peters, 2014).

Para que a expressão monoalélica parental seja estabelecida, cada cluster é regulado por um elemento central de controle in cis, denominado centro de imprinting (ICR; Imprinting Center Region) (Figura I.2). Na linhagem germinativa, as ICR são marcadas por modificações epigenéticas alelo-específicas, como a metilação do DNA, a mais bem caracterizada, e as modificações de histonas (revisão em Peters, 2014). Consequentemente, as ICR ficam ativas 
em apenas um dos dois alelos parentais e regulam coordenadamente a expressão de todos os IG por longas distâncias dentro de um cluster, de maneira alelo-específica (revisões em Delaval e col., 2006; Edwards e Ferguson-Smith, 2006). Diversos estudos mostraram que a deleção de ICR resulta em perda de imprinting de múltiplos genes no cluster, enfatizando a importância desse elemento e sua influência na regulação de regiões multigênicas (revisão em Bartolomei e Ferguson-Smith, 2011). As regiões metiladas nas ICR, de acordo com a origem parental, são denominadas regiões diferencialmente metiladas (DMR; Differentially Methylated Region). Promotores de IG também são diferencialmente metilados e frequentemente atuam como ICR (Edwards e Ferguson-Smith, 2006; Figura I.2).

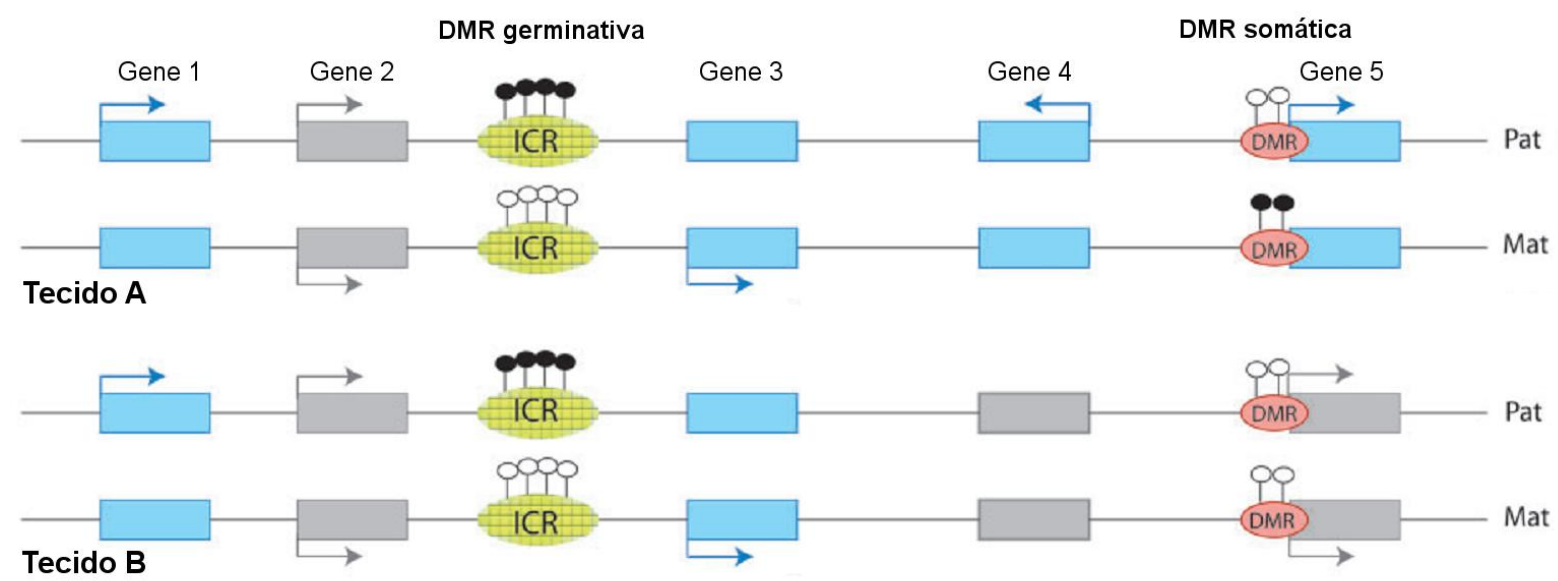

Figura I.2 - Organização de um cluster hipotético sujeito a imprinting genômico, em dois tecidos. Os IG estão representados em azul e os genes de expressão bialélica, em cinza. As setas indicam a orientação da expressão. Em verde está destacada a ICR intergênica, que constitui uma DMR germinativa. Círculos cheios representam DNA metilado e vazios, DNA desmetilado. A ICR está metilada no cromossomo paterno em ambos os tecidos e regula a expressão alelo-específica recíproca dos genes 1 e 3 , este codificando um ncRNA. O gene 2 não é sujeito a imprinting e tem expressão bialélica. O tecido A apresenta uma DMR somática tecido-específica localizada no promotor do gene 5, que codifica um IncRNA; essa DMR está metilada no cromossomo materno e regula a expressão paterna dos genes 4 e 5 nesse tecido. Figura modificada de Henckel e Arnaud (2010).

A metilação de ICR, localizada na região promotora de um gene, silencia sua expressão. ICR não metiladas são consideradas ativas e controlam a expressão de um ou mais IG, por mecanismos que são apenas parcialmente compreendidos; dois modelos foram propostos: o modelo de isoladores (insulators) e o modelo de transcritos de lncRNA (revisão em Peters, 2014). Um exemplo do modelo de insulator é a regulação do lócus H19/IGF2, em 11 p15 (Figura I.3B). Os genes H19 e IGF2 competem por enhancers localizados downstream ao H19. O imprinting recíproco desses genes é controlado pelo centro de imprinting intergênico ICR1, localizado upstream ao H19, que possui sete motivos de ligação a proteínas 
zinc-finger chamadas CTCF (fator de ligação a CCCTC). No alelo materno, o ICR desmetilado permite a ligação das proteínas CTCF, gerando uma barreira (insulator) que impede a aproximação dos enhancers aos promotores de $I G F 2$. Como consequência, o IGF2 fica silenciado e o promotor de H19, com acesso aos enhancers, é ativado. No cromossomo paterno, o ICR1 está metilado, impedindo a ligação das proteínas CTCF, o que permite o acesso dos enhancers aos promotores de IGF2, ativando-o. A metilação do DNA se estende até o promotor de H19, silenciando-o (revisão em Delaval e col., 2006). Outro domínio sujeito a imprinting na região $11 \mathrm{p} 15$, o lócus $K C N Q 1$, é um exemplo do modelo de lncRNA (Figura I.3B). O centro de imprinting ICR2 está localizado no intron 10 do gene $K C N Q 1$ (potassium channel, voltage gated KQT-like subfamily Q, member 1), na região promotora do gene KCNQ1OT1 [KCNQ1 opposite strand/antisense transcript 1 (non-protein coding)]. No cromossomo paterno, o ICR2 está desmetilado, permitindo a expressão de KCNQ1OT1; esse longo transcrito antisense, não codificador, silencia genes próximos in cis, por mecanismo ainda não bem conhecido. No cromossomo materno, em contrapartida, a metilação do ICR2 reprime a atividade do lncRNA, o que permite a expressão de genes vizinhos, incluindo KCNQ1 e CDK1NC [cyclin-dependent kinase inhibitor 1C (p57, Kip2)] (revisão em Kalish e col., 2014).

Os principais clusters de IG, em outros cromossomos, geralmente apresentam o mesmo padrão de regulação do imprinting (Figura I.3): ICR metilados no alelo materno abrigam promotores de lncRNAs, que têm expressão paterna e podem desempenhar papel importante na regulação do imprinting in cis; em contrapartida, ICR metilados no alelo paterno são intergênicos, embora ncRNAs também sejam expressos no alelo oposto (revisões em Edwards e Ferguson-Smith, 2007; Barlow, 2011). Esses mecanismos de regulação do imprinting são conservados entre camundongos e humanos.

A metilação do DNA, adição de grupo metil a resíduos de citosina dos dinucleotídeos $\mathrm{CpG}$, é a principal marca epigenética no estabelecimento e na manutenção do imprinting genômico, mas não é exclusiva a esse fenômeno. Regiões do genoma com alta frequência de dinucleotídeos CpG são denominadas "ilhas CpG" e estão localizadas em promotores, ou em sua proximidade, em aproximadamente $40 \%$ dos genes de mamíferos (Fatemi e col., 2005). A metilação dos promotores gênicos é um mecanismo tecido-específico e reversível de silenciamento, encontrado normalmente em diversos genes. No caso dos IG, entretanto, o estabelecimento das DMR leva à ativação ou inativação gênica nos cromossomos parentais de maneira recíproca (revisão em Biliya e Bulla, 2010). 


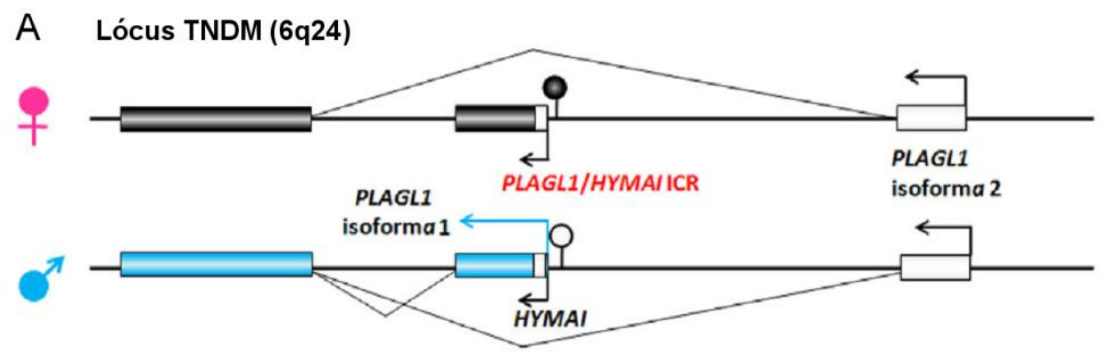

D Lócus PWS/AS (15q11q13)

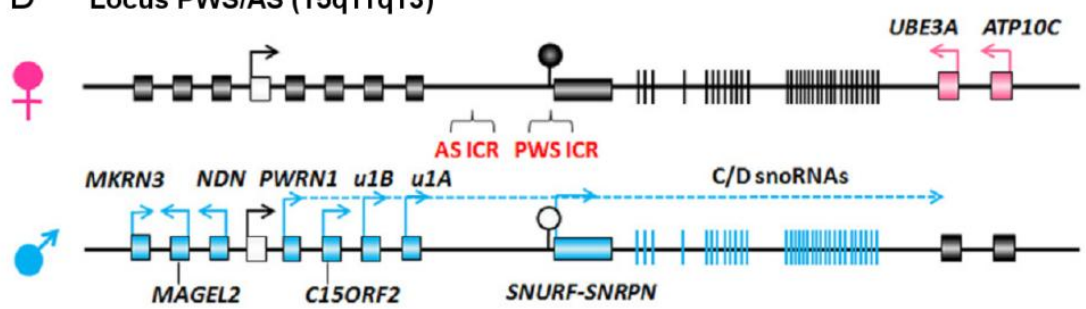

B Lócus SRS/BWS (11p15.5)

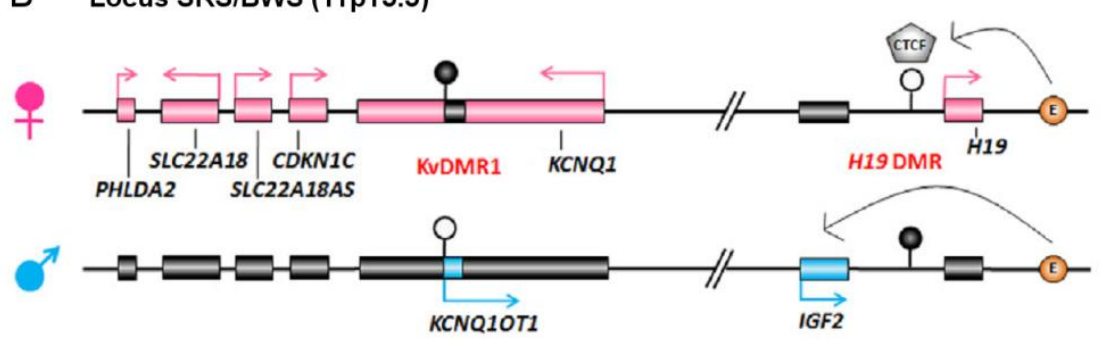

E Lócus PHP (20q13.32)

\section{Lócus UPD(14)pat / UPD(14)mat (14q32)}
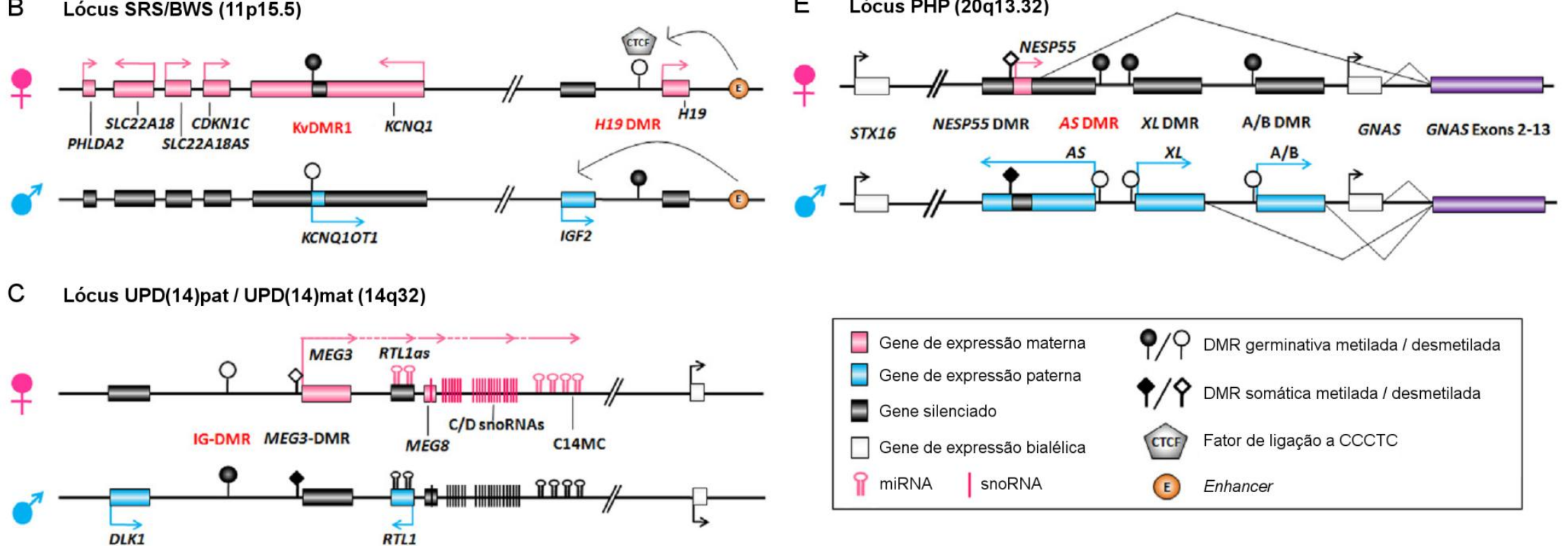

\begin{tabular}{|ll|}
\hline$\square$ Gene de expressão materna & Q/P DMR germinativa metilada / desmetilada \\
$\square$ Gene de expressão paterna & $\$ / \%$ DMR somática metilada / desmetilada \\
$\square$ Gene silenciado & CTCF Fator de ligação a CCCTC \\
$\square$ Gene de expressão bialélica & E Enhancer \\
il miRNA | snoRNA & E
\end{tabular}

Figura I.3 - Clusters sujeitos a imprinting em humanos, associados a síndromes. As DMR em letras vermelhas são ICR. O sentido da transcrição é indicado por setas; orientação para a esquerda = centromérico e para a direita = telomérico. (A) Cluster PLAGL1 associado a diabetes melito neonatal transitória tipo 1 (TNDM). O gene PLAGL1 sofre imprinting e o alelo expresso é o paterno, desmetilado. (B) Cluster em 11p15.5, dividido em domínio centromérico KCNQ1 e domínio telomérico H19/IGF2, associados às síndromes de Silver-Russell (SRS) e Beckwith-Wiedemann (BWS). (C) Cluster DLK1-DIO3 associado às síndromes de UPD(14) materna e paterna. Linhas pontilhas indicam a possível extensão dos transcritos. (D) Cluster SNRPN associado às síndromes de PraderWilli (PWS) e Angelman (AS). (E) Cluster GNAS associado a pseudo-hipoparatireoidismos (PHP). Os primeiros éxons de GNAS, A/B, GNASXL e NESP55 são processados com os éxons 2-13 para gerar diferentes transcritos. Figura modificada de Ishida e Moore (2013). 
Existem dois tipos de DMR em lócus sujeitos a imprinting genômico: DMR germinativas (ou primárias), cujo padrão de metilação é estabelecido durante a gametogênese e mantido em todos os tecidos ao longo do desenvolvimento embrionário e da vida adulta; e DMR somáticas (ou secundárias), que se tornam diferencialmente metiladas após a fertilização, nos promotores de determinados IG, e podem ser tecido-específicas (revisão em Henckel e Arnaud, 2010) (Figura I.2). Uma vez estabelecido numa célula, suas descendentes tem o mesmo alelo metilado de determinado IG.

Outro mecanismo de controle epigenético em lócus sujeitos a imprinting está relacionado à conformação da cromatina. Os alelos de um IG, dependendo da origem parental, podem apresentar modificações específicas nas histonas que compõem a cromatina (acetilação, metilação, ubiquitinação e fosforilação), permitindo ou impedindo a transcrição do DNA (revisão em Verona e col., 2003). Já foi relatada associação entre o alelo parental metilado das ICR e modificações repressivas de histonas, que atuariam na manutenção somática do imprinting (Henckel e col., 2009). De forma geral, as modificações de histonas aparecem relacionadas ao imprinting genômico em associação com a metilação do DNA (revisão em Reik e Walter, 2001).

O imprinting genômico é provavelmente o melhor exemplo de como múltiplos componentes do epigenoma atuam em conjunto na determinação do fenótipo. A metilação do DNA, as modificações de histonas e outros elementos que modelam a cromatina, como os lncRNAs, trabalham coordenadamente na regulação da expressão de IG (revisão em Lambertini, 2014).

\section{I.1.6 Estabelecimento e manutenção do imprinting genômico}

O estabelecimento do imprinting genômico é um processo complexo que inclui a reprogramação epigenética do genoma. As marcas de imprinting devem ser transmitidas com precisão para a geração seguinte e são dependentes da origem parental (Figura I.4A). Em outras palavras, nos machos todas as células contêm um conjunto de cromossomos com marcas de imprinting masculinas (de herança paterna) e outro conjunto com as marcas femininas (de herança materna), mas quando esses cromossomos são transmitidos para a geração seguinte, os dois conjuntos devem ser reprogramados para conter marcas de imprinting apenas masculinas, que será a contribuição paterna. As fêmeas, por sua vez, transmitem para a geração seguinte cromossomos com marcas de imprinting maternas (Figura I.4A). 
A

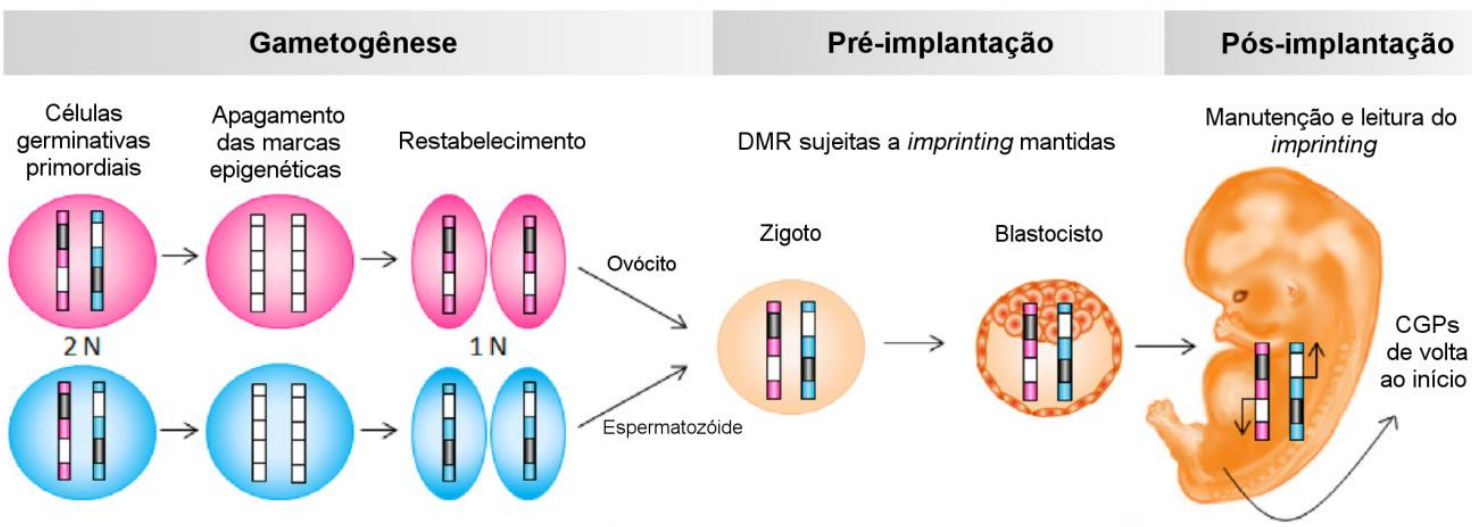

B

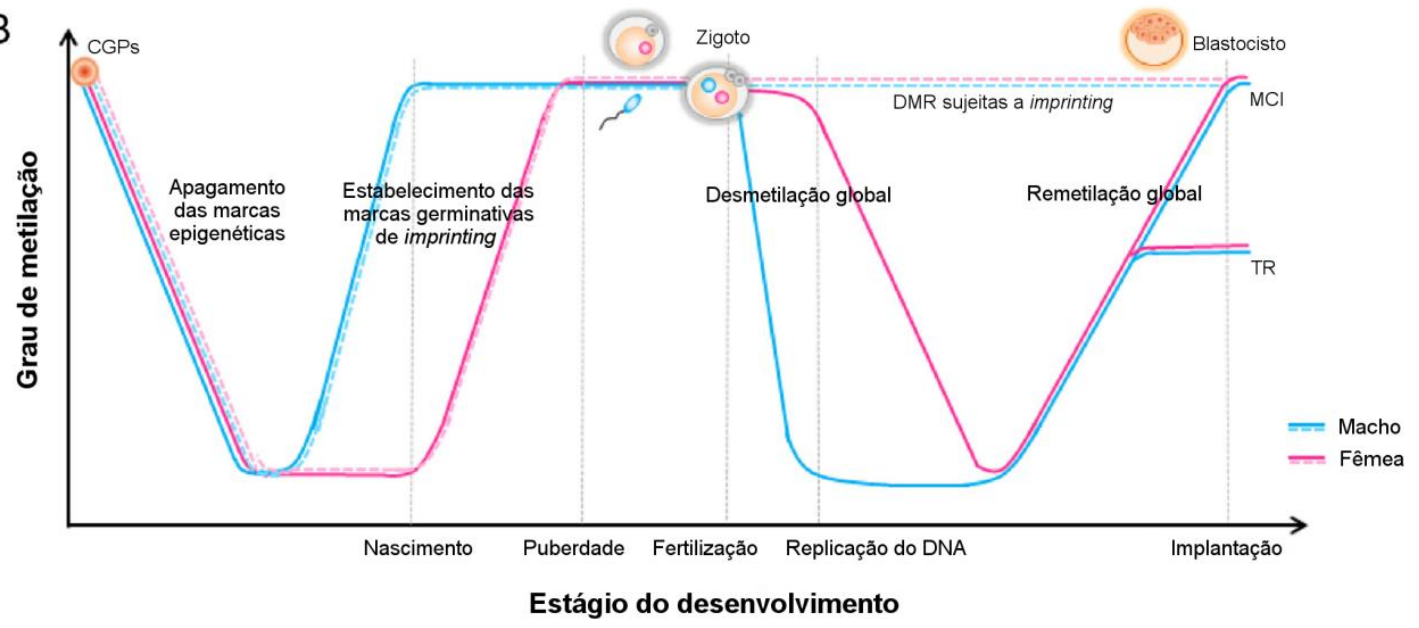

Figura I.4 - Metilação do DNA durante a gametogênese e o início do desenvolvimento embrionário. (A) Apagamento das marcas epigenéticas de imprinting, restabelecimento e manutenção das DMR germinativas ao longo do desenvolvimento. Os cromossomos materno e paterno estão representados por barras rosa e azul, respectivamente. Os boxes pretos e brancos nos cromossomos indicam a presença ou ausência de modificação alélica, respectivamente. As setas partindo dos cromossomos indicam a expressão de alelos não metilados. (B) Reprogramação epigenética do genoma no início do desenvolvimento (baseado em camundongos). Desmetilação global nas células germinativas primordiais (CGP), que apaga as marcas epigenéticas (linhas tracejadas), seguida da metilação de novo para estabelecer novas marcas de imprinting sexo-específicas, durante a gametogênese. Após a fertilização, ocorre a segunda desmetilação global, seguida de remetilação antes do período de implantação do embrião; as DMR sujeitas a imprinting resistem à desmetilação e são mantidas. As células da massa celular interna (MCI; que originarão o feto) apresentam metilação aumentada em relação ao trofectoderma (TF, que originarão a placenta). Figura modificada de Ishida e Moore (2013).

A reprogramação de marcas epigenéticas do genoma (metilação do DNA e modificações de histonas associadas) ocorre em duas fases (Figura I.4B). A primeira acontece durante o desenvolvimento das células germinativas primordiais em ovócitos ou espermatócitos e compreende a desmetilação global, quando se apagam as marcas de imprinting parentais pré-existentes, seguida da metilação de novo do DNA nas ICR, 
estabelecendo-se o novo padrão sexo-específico nos gametas (DMR germinativas) (Figura I.4). A segunda fase de reprogramação ocorre após a fertilização e abrange a desmetilação e a remetilação global antes da implantação do embrião. As ICR germinativas, no entanto, escapam da segunda fase da reprogramação e suas marcas epigenéticas permanecem inalteradas durante o restante do desenvolvimento embrionário e a vida adulta (revisões em Biliya e Bulla, 2010; Ishida e Moore, 2013). Durante a remetilação global, DMR somáticas são estabelecidas. A regulação do imprinting no embrião é complexa, podendo a expressão de IG ser modificada: alguns genes possuem expressão monoalélica somente em determinados tecidos ou tipos celulares, ou em determinado estágio do desenvolvimento; além disso, IG podem apresentar expressão monoalélica isoforma-específica (revisão em Reik e Walter, 2001).

A metilação de novo do DNA é estabelecida pelas metiltransferases de citosina DNMT3A, DNMT3B e DNMT3L. Em camundongos, a Dnmt3a é expressa predominantemente em ovócitos e no início da vida embrionária e, em conjunto com a Dnmt31, é responsável por estabelecer a metilação das ICR nos gametas masculino e feminino; a prole de fêmeas de camundongos $D n m t 3 l^{-/}$não se desenvolve e apresenta ausência completa de metilação materna nas ICR, resultando na expressão desregulada dos IG associados a elas, enquanto a metilação do restante do genoma aparentemente não é afetada (revisão em Henckel e col., 2009). Já a Dnmt3b é expressa em estágios pré-implantacionais do desenvolvimento embrionário e atua na remetilação, após a segunda onda de reprogramação global (revisão em Monk, 2015). Nas células somáticas, o padrão de metilação do DNA é mantido durante o processo de duplicação dos cromossomos e transmitido para as células filhas; quando o DNA é replicado, os grupos metil da fita molde são reconhecidos e novos grupos metil são inseridos na fita em formação pela enzima metiltransferase de manutenção DNMT1 (revisão em Reik e Walter, 2001). O mecanismo pelo qual as metiltransferases se ligam às DMR específicas das células germinativas femininas ou masculinas não é totalmente compreendido, mas provavelmente são necessários fatores que reconheçam as DMR e sejam sexo-específicos na linhagem germinativa (revisão em Bartolomei e Ferguson-Smith, 2011).

A manutenção de identidade parental ao longo do desenvolvimento provavelmente envolve a combinação de sequências de atuação in cis e fatores que atuam in trans. As sequências in cis são presumivelmente as ICR, mas sequências adicionais não podem ser descartadas. Vários fatores de atuação in trans que contribuem para a manutenção do imprinting após a fertilização, impedindo a desmetilação das ICR, foram identificados. 
Algumas dessas proteínas têm impacto na manutenção da metilação do DNA em múltiplos lócus sujeitos a imprinting, ao passo que outras parecem ter papel mais restrito (revisão em Bartolomei e Ferguson-Smith, 2011). Na primeira categoria, Pgc7/Stella, ZFP57, TRIM28 e membros da família NLRP, especificamente NLRP5 e NLRP7, ligam-se aos alelos metilados das ICR, atuando na regulação global do imprinting. Estudos em camundongos knockout mostraram que a ausência de cada um desses fatores resulta na hipometilação de múltiplos ICR, maternos e paternos. Já os fatores Rbbp1/Arid4a e Rbbp1I1/Arid4b atuam na manutenção do imprinting restrita ao lócus Snrpn em camundongos, enquanto que mutação em homozigose no gene $N L R P 2$, de efeito materno, foi associada à hipometilação nos lócus KCNQ1 e PEG1 em pacientes com BWS (revisão em Girardot e col., 2013). Outros fatores, tais como DB1/Vezf1, CTCF, OCT4 e Zfp42 foram associados à manutenção do alelo desmetilado, impedindo sua metilação durante a segunda fase de reprogramação epigenética do genoma (revisão em Monk, 2015)

\section{I.1.7 Manifestações clínicas decorrentes da perda do imprinting em humanos}

O estabelecimento adequado das marcas epigenéticas do imprinting nas células germinativas e a manutenção somática subsequente dessas marcas são cruciais para a regulação da expressão dos IG e, portanto, para o desenvolvimento normal. A desregulação da expressão de IG tem implicações fenotípicas, tanto na infância como na idade adulta. A perda do imprinting genômico pode causar não somente síndromes, mas também está relacionada com o desenvolvimento de doenças comuns complexas, como obesidade, diabetes melito e câncer (revisão em Peters, 2014).

Os IG têm apenas um alelo funcional e normalmente estão arranjados em clusters, com regulação comum. Eles não têm back-up funcional no caso de mutação no único alelo ativo. Ainda, o comprometimento de uma ICR pode alterar o funcionamento de vários genes num cluster sujeito a imprinting. Mecanismos genéticos e epigenéticos podem resultar em perda do imprinting e desregulação da expressão monoalélica dos IG, levando a doenças que se manifestam com transmissão limitada ao sexo.

As alterações genéticas incluem mutações de ponto, deleções, duplicações, e UPD. As mutações de ponto e as alterações do número de cópias de DNA podem afetar diretamente o funcionamento de um ou mais IG. Na UPD, ambas as cópias de um cromossomo ou de parte de um cromossomo são transmitidas de um dos genitores e nenhuma do outro. Dessa forma, as doenças causadas por UPD ocorrem devido à perda ou ganho de expressão dos IG 
localizados no segmento em UPD. As mutações epigenéticas incluem alteração no padrão de metilação da ICR (hipometilação ou hipermetilação) de um cluster sujeito a imprinting, que resulta na desregulação da expressão dos genes regulados em conjunto.

\section{I.1.8 As síndromes de imprinting}

A perda de imprinting genômico já foi identificada como a causa de várias síndromes em humanos (revisão em Biliya e Bulla, 2010). As mais bem caracterizadas são a síndrome de Angelman (AS; MIM \#105830), a síndrome de Prader-Willi (PWS; MIM \#176270), a síndrome de Beckwith-Wiedemann (BWS; MIM \#130650), a síndrome de Silver-Russell (SRS; MIM \#180860), a diabetes melito neonatal transitória tipo 1 (TNDM; MIM \#601410), o pseudo-hipoparatireoidismo tipo 1A (PHP1A; MIM \#103580) e o tipo 1B (PHP1B; MIM \#603233), a síndrome de Temple (TS ou UPD(14)mat; MIM \#616222) e a síndrome de Kagami-Ogata (UPD(14)pat; MIM \#608149). A Tabela I.1 mostra as principais características clínicas e a etiologia de cada uma dessas síndromes, bem como seus modelos em camundongos.

As síndromes de AS e PWS foram as primeiras síndromes decorrentes da perda do imprinting descritas em humanos. Ambas ocorrem com frequência de um em 15 mil nascimentos e estão associadas a alterações do desenvolvimento e comportamentais, além de comprometimento cognitivo. A perda de imprinting é decorrente de mutações (epi)genéticas na porção proximal do braço longo do cromossomo 15 , onde está presente uma ICR que controla vários IG, como ZNF127 (makorin ring finger protein3), NDN [necdin homolog (mouse)], SNRPN (small nuclear ribonucleoprotein polypeptideN), IPW (imprinted in PraderWilli syndrome) e UBE3A (ubiquitin protein ligaseE3A) (revisão em Eggermann e col., 2008). Já as síndromes de SRS e BWS, focos principais deste estudo, são as manifestações clínicas que melhor demonstram a relação entre o imprinting e o crescimento fetal em humanos. Esses dois distúrbios de crescimento são causados por mutações (epi)genéticas opostas em cluster do braço curto do cromossomo 11 (11p15.5), que resultam na desregulação recíproca de IG, como IGF2, H19, CDKN1C, KCNQ1 e KCNQ1OT. 
Tabela I.1 - Síndromes de imprinting em humanos e os modelos correspondentes em camundongos (de acordo com Eggermann e col., 2011; Jacob e col., 2013; Peters, 2014; Mackay e col., 2015; OMIM, NCBI)

\begin{tabular}{|c|c|c|c|c|c|c|}
\hline Síndrome & Frequência & $\begin{array}{l}\text { Localização } \\
\text { cromossômica }\end{array}$ & $\begin{array}{l}\text { Tipo de mutação genética / } \\
\text { epigenética (frequência) }\end{array}$ & $\begin{array}{l}\text { Alteração de expressão } \\
\text { dos principais IG }\end{array}$ & $\begin{array}{l}\text { Principais características } \\
\text { clínicas }\end{array}$ & Modelos em camundongos \\
\hline $\begin{array}{l}\text { Diabetes melito neonatal } \\
\text { transitória tipo } 1 \text { (TNDM) }\end{array}$ & $1 / 800.000$ & $6 q 24$ & $\begin{array}{l}\text { UPD(6)pat (40\%) } \\
\text { Duplicação paterna (30\%) } \\
\text { Hipometilação do ICR materno (30\%) }\end{array}$ & 个PLAGL1 $\uparrow H Y M A I$ & $\begin{array}{l}\text { Hiperglicemia neonatal, } \\
\text { RCIU, macroglossia e } \\
\text { onfalocele }\end{array}$ & $\begin{array}{l}\text { Modelo transgênico com } \\
\text { hiperglicemia neonatal, mas } \\
\text { sem RCIU }\end{array}$ \\
\hline $\begin{array}{l}\text { Síndrome de Silver-Russell } \\
\text { (SRS) }\end{array}$ & $1 / 10.000$ & $7 / 11 \mathrm{p} 15.5$ & $\begin{array}{l}\text { UPD(7)mat (5-10\%) } \\
\text { Alterações cromossômicas (2-4\%) } \\
\text { Hipometilação de ICR1 ( 40\%) }\end{array}$ & $\begin{array}{l}\text { Hipometilação de } \\
\text { H19DMR: } \downarrow \text { IGF2 } \uparrow H 19 \\
\text { Duplicação materna de } \\
\text { 11p15.5: } \text { 个CDKN1C } \\
\text { UPD(7)mat: } M E S T \text { e GRB10 } \\
\text { são principais candidatos }\end{array}$ & $\begin{array}{l}\text { Retardo de crescimento pré } \\
\text { e pós-natal, macrocrania } \\
\text { relativa, assimetria e face } \\
\text { triangular }\end{array}$ & $\begin{array}{l}\text { Modelos com deleção paterna } \\
\text { de } K v D M R 1 \text { ou Igf } 2 \\
\text { apresentaram retardo de } \\
\text { crescimento pré e pós-natal }\end{array}$ \\
\hline $\begin{array}{l}\text { Síndrome de Beckwith- } \\
\text { Wiedemann (BWS) }\end{array}$ & $1 / 15.000$ & $11 \mathrm{p} 15.5$ & $\begin{array}{l}\text { UPD(11p15)pat ( 20\%) } \\
\text { Alterações cromossômicas (1-2\%) } \\
\text { Hipermetilação de ICR1 (5-10\%) } \\
\text { Hipometilação de ICR2 (40-50\%) } \\
\text { Mutação de ponto em CDKN1C (5\%- } \\
\text { 10\%: esporádico; 40-50\%: familial) }\end{array}$ & $\begin{array}{l}\text { UPD(11p15)pat: } \downarrow C D K N 1 C \\
\downarrow H 19 \text { 个IGF2 } \\
\text { Hipermetilação de } \\
\text { H19DMR: } \downarrow H 19 \uparrow I G F 2 \\
\text { Hipometilação de KVDMR1: } \\
\downarrow C D K N 1 C \\
\text { Mutações de ponto: } \\
\downarrow C D K N 1 C\end{array}$ & $\begin{array}{l}\text { Excesso de crescimento pré- } \\
\text { e/ou pós-natal, } \\
\text { macroglossia, onfalocele, } \\
\text { hipoglicemia neonatal, } \\
\text { hemihipertrofia e } \\
\text { predisposição a tumores } \\
\text { embrionários (por exemplo, } \\
\text { tumor de Wilms) }\end{array}$ & $\begin{array}{l}\text { Modelos transgênicos de lgf2 e } \\
\text { knockout de CDKN1C, que } \\
\text { apresentam letalidade fetal e } \\
\text { neonatal; juntos, possuem a } \\
\text { maioria das características da } \\
\text { BWS }\end{array}$ \\
\hline $\begin{array}{l}\text { Síndrome de Temple (TS; } \\
\text { UPD14mat) }\end{array}$ & Rara & $14 q 32$ & $\begin{array}{l}\text { UPD(14)mat (?) } \\
\text { Deleção paterna (?) } \\
\text { Hipometilação de IG-DMR (?) }\end{array}$ & $\downarrow D L K 1 \downarrow R T L 1$ & $\begin{array}{l}\text { Retardo de crescimento pré } \\
\text { e pós-natal, hipotonia, } \\
\text { escoliose, puberdade } \\
\text { precoce e obesidade }\end{array}$ & $\begin{array}{l}\text { Modelo com duplicação distal } \\
\text { do cromossomo } 12 \text { de origem } \\
\text { materna, que apresenta } \\
\text { letalidade perinatal e RCIU }\end{array}$ \\
\hline $\begin{array}{l}\text { Síndrome de Kagami- } \\
\text { Ogata (UPD14pat) }\end{array}$ & Rara & $14 q 32$ & $\begin{array}{l}\text { UPD(14)pat (?) } \\
\text { Deleção materna (?) } \\
\text { Hipermetilação de IG-DMR (?) }\end{array}$ & 个RTL1 & $\begin{array}{l}\text { RCIU, defeitos da parede } \\
\text { torácica e abdominal, } \\
\text { placentomegalia e } \\
\text { polidrâmnio }\end{array}$ & $\begin{array}{l}\text { Modelo com duplicação distal } \\
\text { do cromossomo } 12 \text { de origem } \\
\text { paterna, que apresenta } \\
\text { letalidade pré-natal e } \\
\text { placentomegalia }\end{array}$ \\
\hline
\end{tabular}

RCIU - restrição de crescimento intrauterino; UPD - dissomia uniparental; PTH - hormônio da paratireoide; TSH - hormônio estimulante da tireoide; OHA - osteodistrofia hereditária de 
Tabela I.1 - Síndromes de imprinting em humanos e os modelos correspondentes em camundongo (continuação).

\begin{tabular}{|c|c|c|c|c|c|c|}
\hline Síndrome & Frequência & $\begin{array}{l}\text { Localização } \\
\text { cromossômica }\end{array}$ & $\begin{array}{l}\text { Tipo de mutação genética / } \\
\text { epigenética (frequência) }\end{array}$ & $\begin{array}{l}\text { Alteração de expressão } \\
\text { dos principais IG }\end{array}$ & $\begin{array}{l}\text { Principais características } \\
\text { clínicas }\end{array}$ & Modelos em camundongos \\
\hline $\begin{array}{l}\text { Síndrome de Angelman } \\
\text { (AS) }\end{array}$ & $\begin{array}{l}1 / 20.000- \\
1 / 12.000\end{array}$ & $15 q 11-13$ & $\begin{array}{l}\text { Deleção materna (70\%) } \\
\text { UPD(15)pat (3-7\%) } \\
\text { Alteração de metilação ( 3\%) } \\
\text { Mutação de ponto em UBE3A (10- } \\
\text { 15\%) }\end{array}$ & $\downarrow U B E 3 A$ & $\begin{array}{l}\text { Atraso global do } \\
\text { desenvolvimento, } \\
\text { microcefalia, deficiência } \\
\text { intelectual grave, fala } \\
\text { ausente ou limitada, ataxia, } \\
\text { distúrbio de sono, } \\
\text { convulsões e sorriso } \\
\text { frequente }\end{array}$ & $\begin{array}{l}\text { Quatro modelos } \\
\text { compreendendo knockout do } \\
\text { alelo materno e duplicação } \\
\text { proximal do cromossomo } 7 \text { de } \\
\text { origem paterna, que } \\
\text { apresentam comprometimento } \\
\text { cognitivo, alterações motoras, } \\
\text { ataxia e anormais cerebrais }\end{array}$ \\
\hline $\begin{array}{l}\text { Síndrome de Prader-Willi } \\
\text { (PWS) }\end{array}$ & $\begin{array}{l}1 / 25.000- \\
1 / 10.000\end{array}$ & $15 q 11-13$ & $\begin{array}{l}\text { Deleção paterna (70\%) } \\
\text { UPD(15)mat (20-25\%) } \\
\text { Alteração de metilação ( 1\%) }\end{array}$ & $\downarrow 11$ genes & $\begin{array}{l}\text { Atraso global do } \\
\text { desenvolvimento, baixa } \\
\text { estatura, hipotonia neonatal, } \\
\text { dificuldade de sucção, } \\
\text { hiperfagia, obesidade, } \\
\text { hipogonadismo, disfunção } \\
\text { cognitiva e distúrbios de } \\
\text { comportamento }\end{array}$ & $\begin{array}{l}\text { Diversos modelos que } \\
\text { apresentam características da } \\
\text { PWS, incluindo letalidade } \\
\text { neonatal, dificuldade de } \\
\text { sucção, retardo de crescimento } \\
\text { pós-natal, obesidade adulta, } \\
\text { subfertilidade e defeitos } \\
\text { respiratórios }\end{array}$ \\
\hline $\begin{array}{l}\text { Pseudo- } \\
\text { hipoparatireoidismo tipo } \\
\text { IA (PHP1A) }\end{array}$ & Rara & $20 q 13.3$ & Mutação de ponto em GNAS (?) & $\begin{array}{l}\downarrow G N A S \text { - transcrito de } \\
\text { expressão bialélica } \\
\text { (fenótipo OHA) } \\
\downarrow G N A S \text { - transcrito } \\
\text { NESP55 (obesidade e } \\
\text { resistência hormonal) }\end{array}$ & $\begin{array}{l}\text { Dismorfismos, obesidade, } \\
\text { déficit cognitivo, resistência } \\
\text { renal a PTH, hipocalcemia, } \\
\text { hiperfosfatemia, e } \\
\text { resistência a outros } \\
\text { hormônios }\end{array}$ & $\begin{array}{l}\text { Modelos knockout dos éxons } 1 \\
\text { e } 6 \text { de Gnas no alelo materno, } \\
\text { que apresentam letalidade } \\
\text { neonatal, dismorfismos, } \\
\text { obesidade adulta e resistência } \\
\text { hormonal múltipla }\end{array}$ \\
\hline $\begin{array}{l}\text { Pseudo- } \\
\text { hipoparatireoidismo tipo } \\
\text { IB (PHP1B) }\end{array}$ & Rara & $20 q 13.3$ & $\begin{array}{l}\text { Hipometilação do GNAS A/B-DMR } \\
\text { (15-20\%) } \\
\text { UPD(20)pat (?) }\end{array}$ & $\downarrow G N A S$ - transcrito A/B & $\begin{array}{l}\text { Resistência renal a PTH, } \\
\text { hipocalcemia, } \\
\text { hiperfosfatemia, e } \\
\text { resistência ocasional a TSH }\end{array}$ & $\begin{array}{l}\text { Modelo knockout com } \\
\text { hipometilação materna de } \\
\text { Gnas, que apresenta letalidade } \\
\text { neonatal, resistência a PTH, } \\
\text { hipocalcemia e hiperfosfatemia }\end{array}$ \\
\hline
\end{tabular}

RCIU - restrição de crescimento intrauterino; UPD - dissomia uniparental; PTH - hormônio da paratireoide; TSH - hormônio estimulante da tireoide; OHA - osteodistrofia hereditária de Albright;

$\uparrow$ super-expressão gênica (ativação do alelo silenciado); $\downarrow$ perda de expressão (silenciamento do alelo ativo); (?) - frequência desconhecida na população. 


\section{Síndrome de Silver-Russell}

A SRS foi descrita pela primeira vez por Silver e col. (1953) e Russell (1954). Caracteriza-se principalmente por grave RCIU, seguido de déficit de crescimento pós-natal. Os sinais craniofaciais incluem uma face típica, pequena e triangular, com frontal amplo e micrognatia, podendo os cantos da boca estar voltados para baixo e ocorrer anomalias de orelhas (Figura I.5). A macrocrania relativa ao tamanho do corpo é comum e pelo menos metade dos pacientes apresenta assimetria facial e/ou de membros, e clinodactilia de quintos dedos. Muitas crianças com SRS têm dificuldades para alimentar-se, nos primeiros meses de vida e podem apresentar hipoglicemia. Características menos frequentes incluem manchas café com leite, atraso na maturação óssea e sudorese excessiva. O desenvolvimento neuropsicomotor é normal, na grande maioria dos casos, mas pode ocorrer atraso na aquisição da fala. A manifestação dessas características é muito variável entre os indivíduos afetados. Além disso, o quadro clínico da SRS em adultos é menos marcante do que na infância. A altura média dos pacientes adultos com SRS é de 151,2 \pm 7,8 cm para os homens e 139,9 \pm 9,0 cm para as mulheres (revisão em Eggermann, 2010).

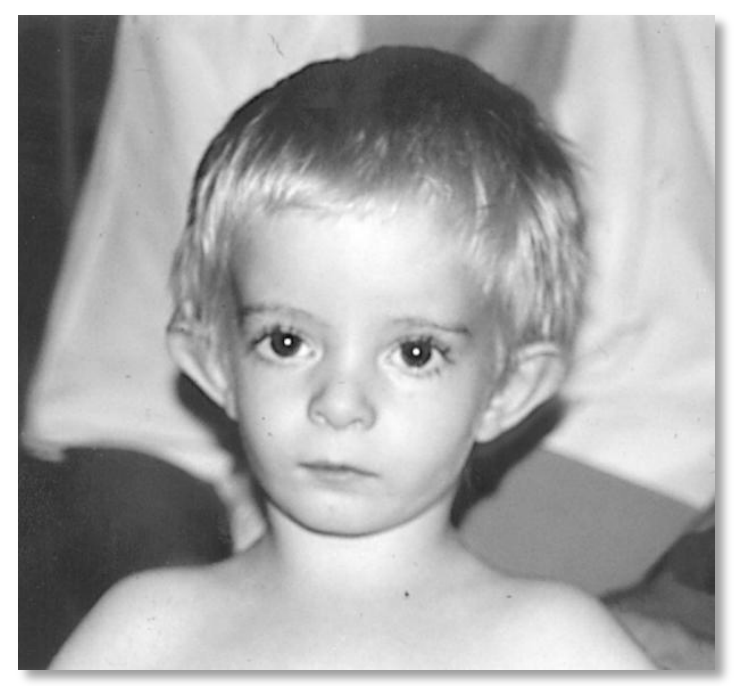

Figura I.5 - Menino com diagnóstico clínico da SRS: macrocrania relativa, face triangular, frontal amplo e assimetria corporal (https://classconnection.s3.amazonaws.com/84/ flashcards/4797084/jpg/f1large-144376287B627575EDE.jpg).

A SRS é geneticamente heterogênea e ocorre, em geral, de forma esporádica. Trata-se da primeira síndrome relacionada a perda de imprinting que afeta dois cromossomos diferentes. Regiões dos cromossomos humanos 7 e 11 sujeitas a imprinting genômico foram associadas com a etiologia da SRS: a UPD(7)mat foi o primeiro mecanismo identificado como causa da síndrome, ocorrendo em 5-10\% dos casos (Kotzot e col., 1995; revisão em 
Eggermann e col., 2012a). O principal gene responsável pela SRS nesse cromossomo ainda não foi identificado. Alterações cromossômicas em 7p11.2-p13, deleções recorrentes em 7q21 e isodissomia segmentar materna abrangendo 7q31-qter em pacientes com quadro clínico compatível com SRS indicaram alguns IG como candidatos para a síndrome: GRB10, SGCE (sarcoglycan epsilon), PEG10 (paternally expressed 10) e MEST (revisão em Eggermann e col., 2012a). No entanto, até o momento nenhuma mutação de ponto ou alteração de metilação foi identificada nesses genes em pacientes com SRS. Num paciente com restrição de crescimento e características típicas de SRS, foi detectada microdeleção de 3,7 Mb em 7q32, abrangendo o gene MEST, fornecendo evidência adicional para a participação desse gene na patologia da síndrome (Eggermann e col., 2012b).

O braço curto do cromossomo 11 humano apresenta um cluster de IG que têm papel crucial no controle do desenvolvimento da placenta e do embrião, e no crescimento fetal. Esse cluster, localizado em 11p15.5, abrange uma região de cerca de $1 \mathrm{Mb}$ e é constituído por dois domínios gênicos, cada um regulado por uma ICR: o domínio telomérico é controlado pela ICR1 (H19DMR), que está metilada no cromossomo paterno, enquanto o mais centromérico é regulado pela ICR2 (KvDMRl), metilada no cromossomo materno (Figura I.6). Alterações genéticas e epigenéticas no segmento $11 \mathrm{p} 15.5$ são as principais causas da SRS. A hipometilação de ICR1 é a causa mais frequente, presente em cerca de $40 \%$ dos casos, e resulta na perda da expressão paterna do gene $I G F 2$, e na expressão bialélica de $H 19$ (revisões em Eggermann e col., 2012a; Jacob e col., 2013). Diversas microduplicações e microdeleções em 11p15, variando de $58 \mathrm{~kb}$ a alguns $\mathrm{Mb}$ de tamanho, foram associadas com a SRS e explicam 2-4\% dos casos (revisão em Begemann e col., 2012). Alguns microdesequilíbrios cromossômicos estão associados com perda de metilação em ICR1. Nos casos de duplicação materna abrangendo a ICR2, o fenótipo aparece devido a super-expressão do gene CDKN1C (Schönherr e col., 2007; Bonaldi e col., 2011). Assim, a etiologia da SRS é explicada em cerca de 50\% dos casos, o que deixa aproximadamente metade dos pacientes sem diagnóstico molecular.

Adicionando à heterogeneidade genética da síndrome, alterações cromossômicas estruturais diversas foram detectadas em pacientes com fenótipo SRS ou SRS-like (quadro clínico atípico), afetando principalmente os cromossomos 7, 8, 15, 17 e 18 (revisão em Fokstuen e col., 2014). Entretanto, além de alterações dos cromossomos 7 e 11, apenas alterações dos cromossomos 15 e 17 foram detectadas em mais de um paciente que preenchiam critérios diagnósticos restritos de SRS (revisões em Hitchins e col., 2001; Eggermann, 2010a). Recentemente, microdesequilíbrios cromossômicos diversos, 
principalmente microdeleções, foram descritos em indivíduos afetados pela SRS, indicando que também podem ser relevantes para a etiologia da síndrome (Bruce e col., 2010; Spengler e col., 2010; Lin e col., 2010; Spengler e col., 2012).

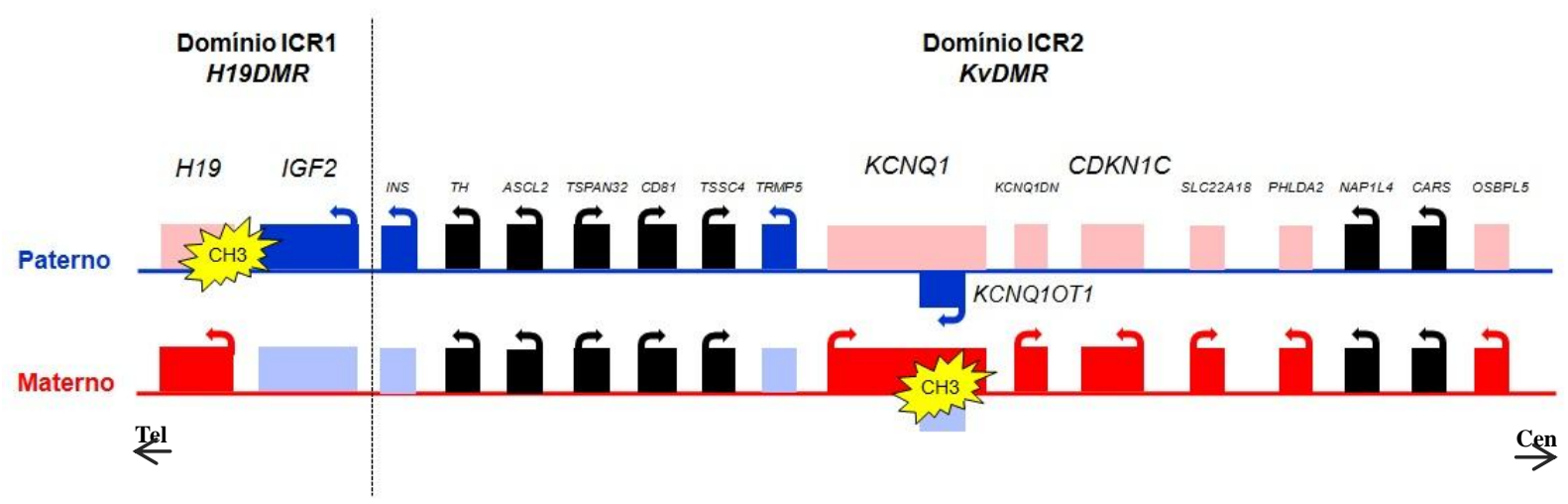

Figura I.6 - Cluster de IG no segmento 11p15.5 do cromossomo 11 humano. As setas indicam genes ativos e a direção da transcrição. Em azul, IG de expressão monoalélica paterna; em vermelho, IG de expressão monoalélica materna; em preto, gene de expressão bialélica. O cluster está dividido em dois domínios, cada um regulado por uma ICR: ICR1 (H19DMR) e ICR2 (KvDMR1). No domínio ICR1, a metilação de H19DMR no cromossomo paterno leva à expressão paterna do gene $I G F 2$ e à expressão materna de H19. No domínio ICR2, a metilação de KvDMR1 no cromossomo materno assegura a expressão paterna do gene KCNQ1OT1 e a expressão materna dos demais IG do domínio.

\section{Síndrome de Beckwith-Wiedemann}

A BWS foi descrita por Beckwith (1963) e Wiedemann (1964). A síndrome é caracterizada principalmente por crescimento exacerbado pré- e/ou pós-natal, macroglossia, hipoglicemia neonatal, assimetria corporal, onfalocele, hérnia umbilical, visceromegalia, predisposição elevada a desenvolver tumores embrionários (como tumor de Wilms e hepatoblastoma), entre outros sinais menos frequentes (Figura I.7); a síndrome, entretanto, é clinicamente heterogênea. A BWS ocorre em geral de forma isolada, com transmissão familial em cerca de 15\% dos casos (revisão em Weksberg e col., 2010).

Alterações genéticas e epigenéticas nos domínios ICR1 e ICR2 em 11p15.5 também estão associadas com a BWS. No entanto, ao contrário do que é visto na SRS, a ICR2 é predominantemente alterada na BWS (revisão em Jacob e col., 2013). A hipometilação de ICR2 é a principal causa da síndrome, e está presente em 40-50\% dos casos. A troca do epigenótipo materno para o paterno na ICR2 leva à expressão bialélica do gene KCNQ1OT1 e à perda de expressão de $C D K N 1 C$. A hipermetilação de ICR1, alteração epigenética oposta àquela observada nessa ICR na SRS, ocorre em 5-10\% dos casos de BWS, e está associada à expressão bialélica do gene IGF2 e à perda de expressão de H19. A UPD segmentar paterna 
de 11 p15.5 é observada em aproximadamente $20 \%$ dos casos e leva à modificação do epigenótipo de ambos os domínios, ICR1 e ICR2, para o epigenótipo paterno; o resultado é desregulação da expressão de todos os IG do cluster, com efeito combinado das duas alterações epigenéticas descritas acima. Mutações de ponto no gene CDKN1C explicam 40$50 \%$ dos casos familiais. Entre os casos esporádicos, mutações de CDKN1C estão presentes em 5-10\% dos pacientes. Diversas alterações cromossômicas em 11p15.5 foram relatadas na BWS, como microduplicações, microdeleções, inversões e translocações. O efeito desses rearranjos cromossômicos na regulação da metilação e expressão dos IG em 11p15.5 é complexo (revisão em Begemann e col., 2012). Na maioria dos casos, no entanto, o efeito na regulação positiva ou negativa de IG específicos é semelhante ao esperado com base nas mutações epigenéticas.

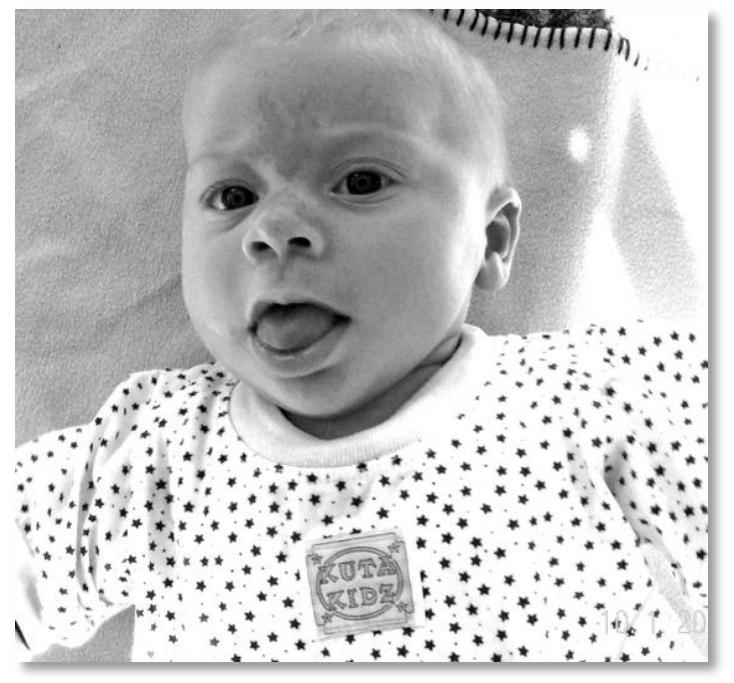

Figura I.7 - Menino com diagnóstico clínico da BWS: crescimento exacerbado e macroglossia. (https://squigglyrainbow.wordpress.com/2011/06/26/squiggly-sunday-3).

A SRS e a BWS representam fenótipos recíprocos causados por desequilíbrios opostos nos níveis de expressão dos IG dos domínios ICR1 e ICR2. Os genes IGF2 e CDKN1C são considerados protagonistas dessa relação: $I G F 2$ codifica um fator de crescimento semelhante à insulina expresso em tecidos mesodérmicos e endodérmicos, enquanto que $C D K N 1 C$ produz um regulador negativo da proliferação e do crescimento celular; ambos são altamente expressos na placenta. IGF2 e CDKN1C agem, respectivamente, como acelerador e freio da transição da fase G1 para S do ciclo celular (Haig, 2015). Em camundongos modelo, o fenótipo da SRS é recapitulado por mutações em heterozigose no $\operatorname{Ig} f 2$, transmitidas via paterna, que resultam em prole e placentas com cerca de metade do tamanho selvagem (DeChiara e col., 1990); a super-expressão de Cdknlc também causa restrição de crescimento 
pré- e pós-natal (Andrews e col., 2007). Já o fenótipo da BWS é recapitulado em camundongos knockout quanto a $C d k n l c$ ou com super-expressão de $I g f 2$, que apresentam crescimento fetal e placentário exacerbados, além de outros sinais característicos da BWS (Eggenschwiler e col., 1997).

As síndromes de Silver-Russell e Beckwith-Wiedemann são os melhores modelos em humanos para se estudar a importância dos IG na regulação da função da placenta e do crescimento fetal. A observação dos papéis antagônicos dos IG no crescimento, em fenótipos opostos, está de acordo com a teoria do conflito parental do imprinting (teoria kinship), no qual genes de expressão paterna promovem o crescimento fetal pela utilização de recursos maternos (ex. $I G F 2$ ), enquanto que genes de expressão materna o suprimem (ex. $C D K N 1 C$ ).

\section{I.1.9 O imprinting genômico e a função cerebral}

A literatura mostra que os IG têm papel importante no desenvolvimento cerebral e no neurocomportamento, muitos sendo expressos no cérebro adulto. Mais de $5 \%$ dos genes que se expressam em cérebro de camundongo estão sujeitos a imprinting, em graus variados (Gregg e col., 2010). Camundongos que apresentam dosagem dos IG reduzida (por deleção gênica) ou aumentada (por UPD) geralmente têm distúrbios de comportamento e alterações cerebrais (revisão em Davies e col., 2007). Em estudo clássico, camundongos quimera, possuindo mistura de células androgenéticas $(\mathrm{Ag})$ ou partenogenéticas $(\mathrm{Pg})$ com células normais, apresentaram diferenças fenotípicas marcantes: quimeras Ag possuíam cérebro pequeno em relação ao tamanho do corpo, enquanto quimeras Pg apresentaram o fenótipo oposto. Além disso, a distribuição das células Ag e Pg nos dois tipos de quimeras diferia, com as células $\mathrm{Pg}$ contribuindo principalmente para o neocortex $\mathrm{e}$ as células $\mathrm{Ag}$, preponderantemente para a região septal, pré-óptica e do hipotálamo (Keverne e col., 1996).

Em camundongos adultos, o imprinting tem papel na amamentação, cuidado materno com a prole, sono, entre outros comportamentos. Já em filhotes, os IG atuam no comportamento alimentar, habilidade de sucção, atividade motora e comunicação com a mãe (revisão em Peters, 2014). A perda do imprinting dos genes Mest e Peg3 resulta em camundongos apresentando comprometimento do cuidado com a prole (Lefebvre e col., 1998a; Curley e col., 2004). Camundongos adultos, com expressão alterada de Grb10 no cérebro, são socialmente dominantes sobre animais selvagens, indicando que o gene de expressão paterna Grb10 tem papel na supressão da dominância social (Garfield e col., 2011). 
Em humanos, os IG expressos no cérebro influenciam comportamentos sociais, alimentares, a emotividade e a cognição. Mutações genéticas e epigenéticas em regiões contendo IG causam síndromes neurológicas, como a PWS e a AS. Pacientes com AS apresentam disposição feliz e podem ter comportamento autista, enquanto que pacientes com PWS frequentemente apresentam instabilidade de humor, acessos de raiva e são suscetíveis a episódios psicóticos (revisão em Peters, 2014). Além dessas síndromes, o aumento da dosagem de IG no segmento 15q11-13 também foi associado a casos não-sindrômicos de psicose, em portadores de alterações cromossômicas de origem materna que abrangiam o lócus (McNamara e col., 2013). Vários transtornos psiquiátricos com comprometimento social, incluindo transtornos do espectro autista mostraram ligação com regiões sujeitas a imprinting ou estavam relacionadas a alterações cromossômicas que supostamente alteram a expressão de IG (revisão em Peters, 2014). Por exemplo, um estudo de ligação indicou que o autismo poderia estar associado a segmentos dos cromossomos 7, 15 e 16, de acordo com a origem parental, sugerindo a influência de IG (Lamb e col., 2005). Algumas doenças neurológicas e neuropsiquiátricas, como a síndrome de Tourette, a esclerose múltipla, a doença de Alzheimer, a esquizofrenia e o transtorno bipolar, parecem ser preferencialmente transmitidas pelo genitor de determinado sexo, sugerindo a participação de IG, apesar de outros mecanismos também poderem explicar esse desvio (revisão em Davies e col., 2007).

Vários IG que não são expressos no cérebro podem também, em teoria, afetar a função neuronal de forma indireta. Por exemplo, genes como Igf2 e Slc38a4 (solute carrier family 38, member 4) possuem papéis importantes na transferência de nutrientes essenciais (glicose, aminoácidos) através das membranas da placenta e a falta ou o excesso desses recursos pode levar a efeitos negativos no neonato, inclusive ao desenvolvimento anormal do cérebro (revisão em Davies e col., 2007). Assim, a forma como os IG afetam o desenvolvimento e a função cerebral durante a embriogênese e o período perinatal é provavelmente complexa e interdependente (revisão em Davies e col., 2007).

\section{I.1.10 O imprinting genômico e o câncer}

A perda global do imprinting em camundongos foi associada com aumento da tumorigênese (Holm e col., 2005). Em humanos, a desregulação do imprinting devido a eventos somáticos ou germinativos, como algumas síndromes de imprinting, a mola hidatiforme completa e o teratoma cístico ovariano, está associada com risco aumentado de câncer (revisão em Peters, 2014). Essa relação não é surpreendente, dada a importância de 
diversos IG em processos como crescimento, diferenciação e controle do ciclo celular. O risco de desenvolver tumores, especialmente os embrionários, como tumor de Wilms e hepatoblastoma, está aumentado em pacientes com BWS.

Vários tipos de câncer em indivíduos não-sindrômicos podem apresentar desregulação da expressão de IG. Apesar de a perda de imprinting de $I G F 2$ ser a alteração mais frequentemente relatada, alterações na expressão de mais de 30 IG já foram descritas em tumores malignos (Murrell, 2006). Um exemplo é a super-expressão do gene RTL1, detectada em um subconjunto de amostras de hepatocarcinoma humano; a super-expressão do gene ortólogo em camundongo, Rtll, promove hepatocarcinogênese (Riordan e col., 2013).

Foi proposto que os conflitos genéticos associadas com a gravidez de mamíferos estão associados com o aumento da vulnerabilidade a câncer (Haig, 2015). A teoria kinship do conflito parental estabelece que genes de expressão materna restringem a proliferação celular e a capacidade invasiva, enquanto que genes de expressão paterna promovem esses processos. Aplicando a teoria kinship do imprinting ao câncer, a expressão alelo-específica aumentaria a vulnerabilidade a tumores, uma vez que a perda da função de IG de expressão materna ou a ativação da cópia materna silenciada de IG normalmente expressos no cromossomo paterno promoveriam proliferação celular e metástase (Summers e col., 2002). Consistente com essas previsões, a expressão do inibidor de quinase dependente de ciclina $C D K N 1 C$ (expressão materna) está frequentemente reduzida no câncer, enquanto que a expressão do fator de crescimento semelhante à insulina IGF2 (expressão paterna) está aumentada (Haig, 2015). 


\section{Conclusões}

A investigação de alterações cromossômicas (sub)microscópicas em pacientes com distúrbios de crescimento revelou $\mathrm{CNV}$ patogênicas/provavelmente patogênicas em 10\% (4/40) dos pacientes investigados; variantes de efeito patogênico desconhecido foram detectadas em 27,5\% (11/40) dos pacientes. A análise do perfil de expressão alelo-específica de IG em pacientes com restrição de crescimento mostrou alterações de expressão em $22 \%$ (4/18); entretanto, a relação dessas alterações com o quadro clínico ainda está por esclarecer. A investigação de metilação global em regiões normalmente hemimetiladas do genoma evidenciou desvios de metilação entre pacientes com restrição de crescimento e indivíduos controle; especificamente, alterações de metilação em genes que atuam em processos de proliferação e diferenciação celulares e crescimento foram detectadas em 45\% (9/20) dos pacientes, sugerindo implicação clínica. $\mathrm{O}$ estudo de paciente portadora de translocação aparentemente equilibrada $\mathrm{t}(5 ; 6)(\mathrm{q} 35.2 ; \mathrm{p} 22.3) \mathrm{dn}$ sugeriu genes candidatos ao quadro clínico, por perda de função ou alteração da regulação, em decorrência da translocação. 


\section{Referências Bibliográficas}

Ambler, G. 2002. Overgrowth. Best Pract. Res. Clin. Endocrinol. Metab. 16: 519-546.

Andrews, SC, Wood, MD, Tunster, SJ, Barton, SC, Surani, MA, John, RM. 2007. Cdkn1c (p57Kip2) is the major regulator of embryonic growth within its imprinted domain on mouse distal chromosome 7. BMC Dev. Biol. 7: 53.

Babak, T, DeVeale, B, Tsang, EK, Zhou, Y, Li, X, Smith, KS, Kukurba, KR, Zhang, R, Li, JB, van der Kooy, D, Montgomery, SB, Fraser, HB. 2015. Genetic conflict reflected in tissue-specific maps of genomic imprinting in human and mouse. Nat. Genet. 47: 544-9.

Baran, Y, Subramaniam, M, Biton, A, Tukiainen, T, Tsang, EK, Rivas, M a, Pirinen, M, GutierrezArcelus, M, Smith, KS, Kukurba, KR, Zhang, R, Eng, C, Torgerson, DG, Urbanek, C, Li, JB, Rodriguez-Santana, JR, Burchard, EG, Seibold, M a, MacArthur, DG, Montgomery, SB, Zaitlen, $\mathrm{N}$ a, Lappalainen, T. 2015. The landscape of genomic imprinting across diverse adult human tissues. Genome Res. 25: 927-936.

Barlow, DP. 2011. Genomic imprinting: a mammalian epigenetic discovery model. Annu. Rev. Genet. 45: 379-403.

Bartolomei, MS, Ferguson-Smith, AC. 2011. Mammalian genomic imprinting. Cold Spring Harb. Perspect. Biol. 3: 1-17.

Begemann, M, Spengler, S, Gogiel, M, Grasshoff, U, Bonin, M, Betz, RC, Dufke, A, Spier, I, Eggermann, T. 2012. Clinical significance of copy number variations in the 11p15.5 imprinting control regions: new cases and review of the literature. J. Med. Genet. 49: 547-53.

Biliya, S, Bulla, L a. 2010. Genomic imprinting: the influence of differential methylation in the two sexes. Exp. Biol. Med. (Maywood). 235: 139-147.

Bloomfield, FH, Spiroski, AM, Harding, JE. 2013. Fetal growth factors and fetal nutrition. Semin. Fetal Neonatal Med. 18: 118-123.

Bonaldi, A, Mazzeu, JF, Costa, SS, Honjo, RS, Bertola, DR, Albano, LMJ, Furquim, IM, Kim, C a, Vianna-Morgante, AM. 2011. Microduplication of the ICR2 domain at chromosome 11p15 and familial Silver-Russell syndrome. Am. J. Med. Genet. A 155A: 2479-83.

Bonapace, G, Concolino, D, Formicola, S, Strisciuglio, P. 2003. A novel mutation in a patient with insulin-like growth factor 1 (IGF1) deficiency. J. Med. Genet. 40: 913-917.

Bruce, S, Hannula-Jouppi, K, Puoskari, M, Fransson, I, Simola, KOJ, Lipsanen-Nyman, M, Kere, J. 2010. Submicroscopic genomic alterations in Silver-Russell syndrome and Silver-Russell-like patients. J. Med. Genet. 47: 816-22.

Charalambous, M, da Rocha, ST, Ferguson-Smith, AC. 2007. Genomic imprinting, growth control and the allocation of nutritional resources: consequences for postnatal life. Curr. Opin. Endocrinol. Diabetes. Obes. 14: 3-12.

Chess, A. 2012. Mechanisms and consequences of widespread random monoallelic expression. Nat. Rev. Genet. 13: 421-428.

Cleaton, M a. M, Edwards, C a., Ferguson-Smith, AC. 2014. Phenotypic Outcomes of Imprinted Gene 
Models in Mice: Elucidation of Pre- and Postnatal Functions of Imprinted Genes. Annu. Rev. Genomics Hum. Genet. 15: 93-126.

Court, F, Tayama, C, Romanelli, V, Martin-Trujillo, A, Iglesias-Platas, I, Okamura, K, Sugahara, N, Simon, C, Moore, H, Harness, J V, Keirstead, H, Sanchez-Mut, JV, Kaneki, E, Lapunzina, P, Soejima, H, Wake, N, Esteller, M, Ogata, T, Hata, K, Nakabayashi, K, Monk, D. 2014. Genomewide parent-of-origin DNA methylation analysis reveals the intricacies of human imprinting and suggests a germline methylation-independent mechanism of establishment. Genome Res. 24: $554-569$.

Cunningham G, Gant FN, Leveno JK, Gilstrap LC, Hauth JC, Wenstrom KD. Williams Obstetrics. 21st ed. United States of America: McGRAW-HILL, Medical Publishing Division, 1819 páginas, 2001.

Curley, JP, Barton, S, Surani, A, Keverne, EB. 2004. Coadaptation in mother and infant regulated by a paternally expressed imprinted gene. Proc. Biol. Sci. 271: 1303-1309.

Das, UG, Sysyn, GD. 2004. Abnormal fetal growth: intrauterine growth retardation, small for gestational age, large for gestational age. Pediatr. Clin. North Am. 51: 639-54, viii.

Dauber, A, Rosenfeld, RG, Hirschhorn, JN. 2014. Genetic Evaluation of Short Stature. J. Clin. Endocrinol. Metab. 99: jc20141506.

Davies, W, Isles, AR, Humby, T, Wilkinson, LS. 2007. What Are Imprinted Genes Doing in the Brain? Epigenetics 2: 201-206.

DeChiara, TM, Efstratiadis, A, Robertson, EJ. 1990. A growth-deficiency phenotype in heterozygous mice carrying an insulin-like growth factor II gene disrupted by targeting. Nature 345: 78-80.

Delaval, K, Wagschal, A, Feil, R. 2006. Epigenetic deregulation of imprinting in congenital diseases of aberrant growth. BioEssays 28: 453-459.

Docherty, LE, Rezwan, FI, Poole, RL, Jagoe, H, Lake, H, Lockett, GA, Arshad, H, Wilson, DI, Holloway, JW, Temple, IK, Mackay, DJG. 2014. Genome-wide DNA methylation analysis of patients with imprinting disorders identifies differentially methylated regions associated with novel candidate imprinted genes. J. Med. Genet. 51: 229-38.

Dunger, DB, Petry, CJ, Ong, KK. 2006. Genetic variations and normal fetal growth. Horm. Res. 65: 34-40.

Edwards, CA, Ferguson-Smith, AC. 2007. Mechanisms regulating imprinted genes in clusters. Curr. Opin. Cell Biol. 19: 281-9.

Eggenschwiler, J, Ludwig, T, Fisher, P, Leighton, P a., Tilghman, SM, Efstratiadis, A. 1997. Mouse mutant embryos overexpressing IGF-II exhibit phenotypic features of he Beckwith-Wiedemann and Simpson-Golabi-Behmel syndromes. Genes Dev. 11: 3128-3142.

Eggermann, T. 2010. Russell-Silver syndrome. Am. J. Med. Genet. Part C Semin. Med. Genet. 154C: $355-364$.

Eggermann, T, Eggermann, K, Schönherr, N. 2008. Growth retardation versus overgrowth: SilverRussell syndrome is genetically opposite to Beckwith-Wiedemann syndrome. Trends Genet. 24: 195-204.

Eggermann, T, Leisten, I, Binder, G, Begemann, M, Spengler, S. 2011. Disturbed methylation at 
multiple imprinted loci : an increasing observation in imprinting disorders. Epigenomics: 625637.

Eggermann, T, Spengler, S, Begemann, M, Binder, G, Buiting, K, Albrecht, B, Spranger, S. 2012b. Deletion of the paternal allele of the imprinted MEST/PEG1 region in a patient with SilverRussell syndrome features. Clin. Genet. 81: 298-300.

Eggermann, T, Spengler, S, Gogiel, M, Begemann, M, Elbracht, M. 2012a. Epigenetic and genetic diagnosis of Silver-Russell syndrome. Expert Rev. Mol. Diagn. 12: 459-471.

Fatemi, M, Pao, MM, Jeong, S, Gal-Yam, EN, Egger, G, Weisenberger, DJ, Jones, P a. 2005. Footprinting of mammalian promoters: Use of a CpG DNA methyltransferase revealing nucleosome positions at a single molecule level. Nucleic Acids Res. 33: 1-2.

Fokstuen, S, Kotzot, D. 2014. Chromosomal rearrangements in patients with clinical features of Silver-Russell syndrome. Am. J. Med. Genet. Part A 164: 1595-1605.

Freathy, RM, Mook-Kanamori, DO, Sovio, U, Prokopenko, I, Timpson, NJ, Berry, DJ, Warrington, NM, Widen, E, Hottenga, JJ, Kaakinen, M, Lange, L a, Bradfield, JP, Kerkhof, M, Marsh, J a, Mägi, R, Chen, C-M, Lyon, HN, Kirin, M, Adair, LS, Aulchenko, YS, Bennett, AJ, Borja, JB, Bouatia-Naji, N, Charoen, P, Coin, LJM, Cousminer, DL, de Geus, EJC, Deloukas, P, Elliott, P, Evans, DM, Froguel, P, Glaser, B, Groves, CJ, Hartikainen, A-L, Hassanali, N, Hirschhorn, JN, Hofman, A, Holly, JMP, Hyppönen, E, Kanoni, S, Knight, B a, Laitinen, J, Lindgren, CM, McArdle, WL, O'Reilly, PF, Pennell, CE, Postma, DS, Pouta, A, Ramasamy, A, Rayner, NW, Ring, SM, Rivadeneira, F, Shields, BM, Strachan, DP, Surakka, I, Taanila, A, Tiesler, C, Uitterlinden, AG, van Duijn, CM, Wijga, AH, Willemsen, G, Zhang, H, Zhao, J, Wilson, JF, Steegers, E a P, Hattersley, AT, Eriksson, JG, Peltonen, L, Mohlke, KL, Grant, SF a, Hakonarson, H, Koppelman, GH, Dedoussis, G V, Heinrich, J, Gillman, MW, Palmer, LJ, Frayling, TM, Boomsma, DI, Davey Smith, G, Power, C, Jaddoe, VW V, Jarvelin, M-R, McCarthy, MI. 2010. Variants in ADCY5 and near CCNL1 are associated with fetal growth and birth weight. Nat. Genet. 42: 430-435.

Garfield, AS, Cowley, M, Smith, FM, Moorwood, K, Stewart-Cox, JE, Gilroy, K, Baker, S, Xia, J, Dalley, JW, Hurst, LD, Wilkinson, LS, Isles, AR, Ward, A. 2011. Distinct physiological and behavioural functions for parental alleles of imprinted Grb10. Nature 469: 534-538.

Gascoin-Lachambre, G, Buffat, C, Rebourcet, R, Chelbi, ST, Rigourd, V, Mondon, F, Mignot, T-M, Legras, E, Simeoni, U, Vaiman, D, Barbaux, S. 2010. Cullins in Human Intra-Uterine Growth Restriction: Expressional and Epigenetic Alterations. Placenta 31: 151-157.

Gicquel, C, Le Bouc, Y. 2006. Hormonal regulation of fetal growth. Horm. Res. 65: 28-33.

Girardot, M, Feil, R, Llères, D. 2013. Epigenetic deregulation of genomic imprinting in humans: causal mechanisms and clinical implications. Epigenomics 5: 715-28.

Graham, CF. 1974. The production of parthenogenetic mammalian embryos and their use in biological research. Biol. Rev. Camb. Philos. Soc. 49: 399-424.

Gregg, C. 2014. Known unknowns for allele-specific expression and genomic imprinting effects. F1000Prime Rep. 6.

Haig, D. 2015. Maternal-fetal conflict, genomic imprinting and mammalian vulnerabilities to cancer. Philos. Trans. R. Soc. B Biol. Sci. 370: 20140178. 
Hall, JG. 2010. Review and hypothesis: syndromes with severe intrauterine growth restriction and very short stature--are they related to the epigenetic mechanism(s) of fetal survival involved in the developmental origins of adult health and disease? Am. J. Med. Genet. A 152A: 512-27.

Henckel, A, Arnaud, P. 2010. Genome-wide identification of new imprinted genes. Brief. Funct. Genomics 9: 304-14.

Henckel, A, Nakabayashi, K, Sanz, LA, Feil, R, Hata, K, Arnaud, P. 2009. Histone methylation is mechanistically linked to DNA methylation at imprinting control regions in mammals. Hum. Mol. Genet. 18: 3375-3383.

Hitchins, MP, Stanier, P, Preece, MA, Moore, GE. 2001. Silver-Russell syndrome: a dissection of the genetic aetiology and candidate chromosomal regions. J. Med. Genet. 38: 810-819.

Holm, TM, Jackson-Grusby, L, Brambrink, T, Yamada, Y, Rideout 3rd, WM, Jaenisch, R. 2005. Global loss of imprinting leads to widespread tumorigenesis in adult mice. Cancer Cell 8: 275285.

Ishida, M, Moore, GE. 2013. The role of imprinted genes in humans. Mol. Aspects Med. 34: 826-40.

Jacob, KJ, Robinson, WP, Lefebvre, L. 2013. Beckwith-Wiedemann and Silver-Russell syndromes: opposite developmental imbalances in imprinted regulators of placental function and embryonic growth. Clin. Genet. 84: 326-34.

Kalish, JM, Jiang, C, Bartolomei, MS. 2014. Epigenetics and imprinting in human disease. Int. J. Dev. Biol. 58: 291-298.

Keverne, EB, Curley, JP. 2008. Epigenetics, brain evolution and behaviour. Front. Neuroendocrinol. 29: $398-412$.

Keverne, EB, Fundele, R, Narasimha, M, Barton, SC, Surani, MA. 1996. Genomic imprinting and the differential roles of parental genomes in brain development. Dev. Brain Res. 92: 91-100.

Kotzot, D, Schmitt, S, Bernasconi, F, Robinson, WP, Lurie, IW, Ilyina, H, Méhes, K, Hamel, BC, Otten, BJ, Hergersberg, M. 1995. Uniparental disomy 7 in Silver-Russell syndrome and primordial growth retardation. Hum. Mol. Genet. 4: 583-7.

Lamb, J a, Barnby, G, Bonora, E, Sykes, N, Bacchelli, E, Blasi, F, Maestrini, E, Broxholme, J, Tzenova, J, Weeks, D, Bailey, AJ, Monaco, AP. 2005. Analysis of IMGSAC autism susceptibility loci: evidence for sex limited and parent of origin specific effects. J. Med. Genet. 42: $132-7$.

Lango Allen, H, Estrada, K, Lettre, G, Berndt, SI, Weedon, MN, Rivadeneira, F, Willer, CJ, Jackson, AU, Vedantam, S, Raychaudhuri, S, Ferreira, T, Wood, AR, Weyant, RJ, Segrè, A V., Speliotes, EK, Wheeler, E, Soranzo, N, Park, J-H, Yang, J, Gudbjartsson, D, Heard-Costa, NL, Randall, JC, Qi, L, Vernon Smith, A, Mägi, R, Pastinen, T, Liang, L, Heid, IM, Luan, J, Thorleifsson, G, Winkler, TW, Goddard, ME, Sin Lo, K, Palmer, C, Workalemahu, T, Aulchenko, YS, Johansson, Å, Carola Zillikens, M, Feitosa, MF, Esko, T, Johnson, T, Ketkar, S, Kraft, P, Mangino, M, Prokopenko, I, Absher, D, Albrecht, E, Ernst, F, Glazer, NL, Hayward, C, Hottenga, J-J, Jacobs, KB, Knowles, JW, Kutalik, Z, Monda, KL, Polasek, O, Preuss, M, Rayner, NW, Robertson, NR, Steinthorsdottir, V, Tyrer, JP, Voight, BF, Wiklund, F, Xu, J, Hua Zhao, J, Nyholt, DR, Pellikka, N, Perola, M, Perry, JRB, Surakka, I, Tammesoo, M-L, Altmaier, EL, Amin, N, Aspelund, T, Bhangale, T, Boucher, G, Chasman, DI, Chen, C, Coin, L, Cooper, MN, 
Dixon, AL, Gibson, Q, Grundberg, E, Hao, K, Juhani Junttila, M, Kaplan, LM, Kettunen, J, König, IR, Kwan, T, Lawrence, RW, Levinson, DF, Lorentzon, M, McKnight, B, Morris, AP, Müller, M, Suh Ngwa, J, Purcell, S, Rafelt, S, et al. 2010. Hundreds of variants clustered in genomic loci and biological pathways affect human height. Nature 467: 832-838.

Lefebvre, L, Viville, S, Barton, SC, Ishino, F, Keverne, EB, Surani, M a. 1998. Abnormal maternal behaviour and growth retardation associated with loss of the imprinted gene Mest. Nat. Genet. 20: $163-169$.

Lin, S-Y, Lee, C-N, Hung, C-C, Tsai, W-Y, Lin, S-P, Li, N-C, Hsieh, W-S, Tung, Y-C, Niu, D-M, Hsu, W-M, Chen, L-Y, Fang, M-Y, Tu, M-P, Kuo, P-W, Lin, C-Y, Su, Y-N, Ho, H-N. 2010. Epigenetic profiling of the $\mathrm{H} 19$ differentially methylated region and comprehensive whole genome array-based analysis in Silver-Russell syndrome. Am. J. Med. Genet. A 152A: 2521-8.

Mackay, DJG, Eggermann, T, Buiting, K, Garin, I, Netchine, I, Linglart, A, de Nanclares, GP. 2015. Multilocus methylation defects in imprinting disorders. Biomol. Concepts 6: 1-11.

Malan, V, Chevallier, S, Soler, G, Coubes, C, Lacombe, D, Pasquier, L, Soulier, J, MorichonDelvallez, N, Turleau, C, Munnich, A, Romana, S, Vekemans, M, Cormier-Daire, V, Colleaux, L. 2010. Array-based comparative genomic hybridization identifies a high frequency of copy number variations in patients with syndromic overgrowth. Eur. J. Hum. Genet. 18: 227-232.

McGrath, J, Solter, D. 1984. Completion of mouse embryogenesis requires both the maternal and paternal genomes. Cell 37: 179-183.

McNamara, GI, Isles, AR. 2013. Dosage-sensitivity of imprinted genes expressed in the brain: 15q11q13 and neuropsychiatric illness. Biochem. Soc. Trans. 41: 721-6.

Monk, D. 2015. Germline-derived DNA methylation and early embryo epigenetic reprogramming: The selected survival of imprints. Int. J. Biochem. Cell Biol. 67: 128-138.

Monk, D, Moore, GE. 2004. Intrauterine growth restriction--genetic causes and consequences. Semin. Fetal Neonatal Med. 9: 371-378.

Moore, GE, Ishida, M, Demetriou, C, Al-Olabi, L, Leon, LJ, Thomas, AC, Abu-Amero, S, Frost, JM, Stafford, JL, Chaoqun, Y, Duncan, AJ, Baigel, R, Brimioulle, M, Iglesias-Platas, I, Apostolidou, S, Aggarwal, R, Whittaker, JC, Syngelaki, A, Nicolaides, KH, Regan, L, Monk, D, Stanier, P. 2015. The role and interaction of imprinted genes in human fetal growth. Philos. Trans. R. Soc. B Biol. Sci. 370: 1-12.

Moore, T, Haig, D. 1991. Genomic imprinting in mammalian development: a parental tug-of-war. Trends Genet. 7: 45-49.

Morison, IM, Ramsay, JP, Spencer, HG. 2005. A census of mammalian imprinting. Trends Genet. 21: 457-65.

Murrell, A. 2006. Genomic imprinting and cancer: from primordial germ cells to somatic cells. ScientificWorldJournal. 6: 1888-1910.

Ogilvy-Stuart, a L, Soos, M a, Hands, SJ, Anthony, MY, Dunger, DB, O’Rahilly, S. 2001. Hypoglycemia and resistance to ketoacidosis in a subject without functional insulin receptors. J. Clin. Endocrinol. Metab. 86: 3319-26.

Okubo, Y, Siddle, K, Firth, H, O’Rahilly, S, Wilson, LC, Willatt, L, Fukushima, T, Takahashi, S, 
Petry, CJ, Saukkonen, T, Stanhope, R, Dunger, DB. 2003. Cell proliferation activities on skin fibroblasts from a short child with absence of one copy of the type 1 insulin-like growth factor receptor (IGF1R) gene and a tall child with three copies of the IGF1R gene. J. Clin. Endocrinol. Metab. 88: 5981-8.

Peters, J. 2014. The role of genomic imprinting in biology and disease: an expanding view. Nat. Rev. Genet. 15: 517-530.

Reik, W, Walter, J. 2001. Genomic imprinting: parental influence on the genome. Nat. Rev. Genet. 2: 21-32.

Riordan, JD, Keng, VW, Tschida, BR, Scheetz, TE, Bell, JB, Podetz-Pedersen, KM, Moser, CD, Copeland, NG, Jenkins, NA, Roberts, LR, Largaespada, DA, Dupuy, AJ. 2013. Identification of rtl1, a retrotransposon-derived imprinted gene, as a novel driver of hepatocarcinogenesis. PLoS Genet. 9: e1003441.

Saenger, P, Reiter, E. 2012. Genetic factors associated with small for gestational age birth and the use of human growth hormone in treating the disorder. Int. J. Pediatr. Endocrinol. 2012: 12.

Schönherr, N, Meyer, E, Roos, A, Schmidt, A, Wollmann, HA, Eggermann, T. 2007. The centromeric 11 p15 imprinting centre is also involved in Silver-Russell syndrome. J. Med. Genet. 44: 59-63.

Seaver, LH, Irons, M. 2009. ACMG practice guideline: Genetic evaluation of short stature. Genet. Med. 11: 465-470.

Spengler, S, Begemann, M, Ortiz Brüchle, N, Baudis, M, Denecke, B, Kroisel, PM, Oehl-Jaschkowitz, B, Schulze, B, Raabe-Meyer, G, Spaich, C, Blümel, P, Jauch, A, Moog, U, Zerres, K,

Eggermann, T. 2012. Molecular karyotyping as a relevant diagnostic tool in children with growth retardation with Silver-Russell features. J. Pediatr. 161: 933-42.

Spengler, S, Schönherr, N, Binder, G, Wollmann, H a, Fricke-Otto, S, Mühlenberg, R, Denecke, B, Baudis, M, Eggermann, T. 2010. Submicroscopic chromosomal imbalances in idiopathic SilverRussell syndrome (SRS): the SRS phenotype overlaps with the 12q14 microdeletion syndrome. J. Med. Genet. 47: 356-60.

Summers, K, Da Silva, J, Farwell, M a. 2002. Intragenomic conflict and cancer. Med. Hypotheses 59: $170-179$.

Sun, FL, Dean, WL, Kelsey, G, Allen, ND, Reik, W. 1997. Transactivation of Igf 2 in a mouse model of Beckwith-Wiedemann syndrome. Nature 389: 809-815.

Surani, MA, Barton, SC, Norris, ML. 1984. Development of reconstituted mouse eggs suggests imprinting of the genome during gametogenesis. Nature 308: 548-550.

Verona, RI, Mann, MRW, Bartolomei, MS. 2003. Genomic Imprinting: Intricacies of Epigenetic Regulation in Clusters. Annu. Rev. Cell Dev. Biol. 19: 237-259.

Weissmann-Brenner, A, Simchen, MJ, Zilberberg, E, Kalter, A, Weisz, B, Achiron, R, Dulitzky, M. 2012. Maternal and neonatal outcomes of large for gestational age pregnancies. Acta Obstet. Gynecol. Scand. 91: 844-849.

Weksberg, R, Shuman, C, Beckwith, JB. 2010. Beckwith-Wiedemann syndrome. Eur. J. Hum. Genet. 18: 8-14.

Woods, KA, Camacho-Hübner, C, Savage, MO, Clark, AJL. 1996. Intrauterine Growth Retardation 
and Postnatal Growth Failure Associated with Deletion of the Insulin-Like Growth Factor I Gene. N. Engl. J. Med. 335: 1363-1367.

Yachelevich, N. 2015. Generalized Overgrowth Syndromes With Prenatal Onset. Curr. Probl. Pediatr. Adolesc. Health Care 45: 97-111.

Yaghootkar, H, Freathy, RM. 2012. Genetic origins of low birth weight. Curr. Opin. Clin. Nutr. Metab. Care 15: 258-64.

Yang, J, Benyamin, B, McEvoy, BP, Gordon, S, Henders, AK, Nyholt, DR, Madden, PA, Heath, AC, Martin, NG, Montgomery, GW, Goddard, ME, Visscher, PM. 2010. Common SNPs explain a large proportion of the heritability for human height. Nat. Genet. 42: 565-569.

Zahnleiter, D, Uebe, S, Ekici, AB, Hoyer, J, Wiesener, A, Wieczorek, D, Kunstmann, E, Reis, A, Doerr, HG, Rauch, A, Thiel, CT. 2013. Rare Copy Number Variants Are a Common Cause of Short Stature. PLoS Genet. 9: 1-11. 